\title{
Estimating the Direct and Indirect Impact of Typhoons on Plant Performance: Evidence from Chinese Manufacturers
}

\author{
May 22, 2019
}

\begin{abstract}
We quantify the impact of typhoons on manufacturing plants in China. To this end we construct a panel data set of precisely geo-located plants and a plant-level measure of typhoon damage derived from storm track data and a wind field model. Our econometric results reveal that the impact on plant sales can be considerable, although the effects are relatively short-lived. Annual total costs to Chinese plants from typhoons are estimated to be in the range of US\$ 3.2 billion (2017 prices), or about 1 per cent of average turnover. When we examine the channels by which plants react to a storm event we find that there is some buffering through an increase in debt and a reduction in liquidity. In terms of propagating the shock through foreign or domestic channels, our estimates suggest that 28 plants prefer to reduce sales to domestic buyers more than foreign buyers and purchases from foreign rather than domestic suppliers. We also find some evidence of a negative indirect effect on turnover through spillovers from customers and a positive effect through damage to very nearby competitors.
\end{abstract}

Keywords: China, Typhoons, Wind field model, Plants, Economic impact. JEL codes: O17, O44 and Q54. 


\section{Introduction}

For those countries that are susceptible to tropical cyclone strikes, the prediction that their intensity may increase with climate change underlines the importance of understanding and being able to quantify the economic consequences of these storms (Knutson et al., 2010; Emanuel, 2013). Much of the existing literature on the impact of tropical cyclones has tended to focus on national or regional effects and the results have been rather mixed. ${ }^{1}$ However, while insightful, these macroeconomic studies are fairly limited in terms of providing useful information for formulating policies to build resilience. More specifically, tropical storms, as with most natural disasters, are inherently very local in nature and the local impact will likely be, at least to some extent, 'aggregated out' if a too broader regional unit of analysis is used. ${ }^{2}$ Hence, it is argued that any real understanding, and therefore what to target in terms of disaster management policy, can only be derived from more micro-level studies at the level of the individual, household, or firm. However, to date, the existing evidence in this regard is relatively scarce and also provides inconsistent results due in part to different methodological approaches (see e.g., Leiter et al., 2009; Coelli \& Manasse, 2014; Ando \& Kimura, 2012; Tanaka, 2015; Basker \& Miranda, 2017; Cole et al., 2019).

The challenge for researchers wishing to conduct a micro-level analysis of tropical storms is threefold. First, the economic unit of analysis needs to be observed before and after a storm event, and any possible relocation tracked in order to be able to derive plausible inference. Second, it is important to model the impact of the storm locally, which means considering the complex spatially heterogeneous nature of storms to enable one to capture the fact that relatively small differences in distance can result in considerable differences in damage. To this end there has been considerable progress in the economics literature as research has evolved from using simple event indicators or likely endogenous ex-post measured damages to employing physical models to approximate the local impact (see e.g., Strobl, 2012). The remaining, and perhaps greatest challenge, is being able to precisely localize the economic agents of interest so that they match the spatial heterogeneity of the storm impact. The difficulty with localizing economic agents, however, is that the majority of available firm, household or farm data used in existing micro-level studies, do not provide exact locations

\footnotetext{
${ }^{1}$ The early literature has tended to take a cross-country macroeconomic approach to examine the impact of a disaster on growth. Examples include Loayza et al. (2012), Strobl (2012), Ahlerup (2013), and Crespo Cuaresma et al. (2008). Intuition would suggest the impact of a disaster should be "naturally negative" (Felbermayr \& Gröschl, 2014) and the results of Hsiang and Jina (2014) suggest a long-term negative impact of cyclones on growth. However, other studies have recorded an overall positive effect in cases where there is an element of creative destruction as a result of "building back better" Albala-Bertrand (1993). In a recent study, using a stochastic endogenous growth model, Bakkensen and Barrage (2018) attempt to bridge the gap between macro and micro evidence on the impact of climate shocks on growth by estimating the impact of cyclones on the structural determinants of growth. See Noy and duPont IV (n.d.) for a summary of the macroeconomic studies.

${ }^{2}$ A number of papers investigate the "aggregation problem" by using satellite derived nightlight data to measure the impact of hurricanes and typhoons. For example, using yearly data Strobl (2011), Bertinelli and Strobl (2013) and Elliott et al. (2015) show that for hurricanes and typhoons, national level regressions can mask much of the impact at the local regional level. More recently Del Valle et al. (2018) use monthly nightlight intensity for the first time to measure the local impact of tropical cyclones within a given year for Guangdong province in Southern China.
} 
and instead rely on fairly broad administrative regions. ${ }^{3}$

This paper attempts to overcome the aforementioned challenges by explicitly spatially modeling potential damages from typhoons (the name given to tropical cyclones in the Northwestern Pacific region) using features of the storm and linking these to a panel of Chinese manufacturing plants while also controlling for potentially climatic confounding factors (local rainfall and temperature). China arguably represents an ideal country to study as it is subject to around 5.8 damaging storms per year and, importantly, these storms have caused considerable damage to its coast where much of the recently expanded manufacturing activity is located. Q. Zhang et al. (2009) show that total economic losses and hence vulnerability to tropical cyclones in China have been increasing over time and Fischer et al. (2015) estimate economic losses from tropical cyclones in China for our period 2000-2006 to be in the region on US $\$ 9.05$ billion (2017 prices) annually. ${ }^{4}$

Our contribution to the current literature is three-fold. First, we follow previous studies that model damages due to tropical cyclones locally via a physical wind field model, but are able to do so much more precisely by identifying the exact location of each plant by using detailed address information. ${ }^{5}$ Second, using our geo-localized panel of Chinese manufacturing plants and the associated typhoon damages we are the first that are able to not only quantify the impact of these storms on various aspects of plant performance, but also identify the channels by which plants react to the exogenous shock, including changes to liquidity and debt ratios, depletion of inventories, and imports of intermediate inputs and exports. ${ }^{6}$ Finally, we contribute to the literature on local supply chains by generating a number of spatial spillover indices to capture the typhoon damage on suppliers, customers and competitors and to estimate whether possible spatial linkages indirectly impact the performance of our plants.

There are a number of studies that are related to what we do in this paper. One of the closest is Leiter et al. (2009) who examine the impact on firms of being located within a flood hit region. However, although they are able to control for individual firm level characteristics they are not able to identify whether any particular firm was inundated (they

\footnotetext{
${ }^{3}$ Broad administrative regions are used in, among others, Paxson and Rouse (2008), Leiter et al. (2009), Craioveanu and Terrell (2016), and Groen, Kutzbach, and Polivka (2017).

${ }^{4}$ The numbers in Fischer et al. (2015) are from the CMA National Survey of Economic Losses at County Level (1984-2003) (2014), the China Climate Impact Assessment Reports (2001-2010) (2014), and from the Yearbooks of Meteorological Disaster (2011-2013) (2014) and have been used to calculate direct economic loss for affected populations due to land falling tropical cyclones that strike mainland China (including Hainan). An illustrative case is the 2006 Typhoon Saomai which struck the provinces of Zhejiang and Fujian and left thousands of building destroyed, power cuts in six cities, the sinking of thousands of boats and the evacuation of up to 1.7 million people with costs estimated by the Chinese government to be in the region of $\$$ US 4.3 billion (2017 prices). Han et al. (2016) provide a summary of China's major disasters and their associated damages between 1985 and 2014 and Lixin et al. (2012) provide an integrated risk assessment of multiple hazards in China. For a description and analysis of China's disaster management planning system see the Natural Disaster Data Book published by Asian Disaster Reduction Center and studies by Shi et al. (2007), Lixin et al. (2012), and Z. Wang et al. (2016).

${ }^{5}$ For examples of different wind-field modelling approaches see Strobl (2012) and Hsiang and Jina (2014).

${ }^{6} \mathrm{Tol}(1999)$ argues that to understand the impact of disasters on firms at the local level it is important to consider firm specific characteristics.
} 
assume their broad flood measure captures the cumulative impact of the flood on inputs and productivity). Their results show that firms in flooded areas experience stronger growth in employment and capital accumulation in the short-run compared with unaffected firms although they also find a short-term negative impact on productivity. In another paper on the impact of flooding on firm performance, Coelli and Manasse (2014) find that the value added of Italian firms hit by a flood was $6.9 \%$ higher than unaffected firms two years later driven in part by government aid that contributed around $2 \%$ to this additional growth. This finding is consistent with a build back better effect and the notion that if more capital is destroyed than labor in a local area, the return to capital may increase leading to a short-term growth impact. ${ }^{7}$

Cole et al. (2019) is also close in spirit to our paper in using a plant specific measure of damage, although this is constructed using ex-post measured damages from a ground survey and thus possibly subject to omitted variable bias. In their study of the 1995 Kobe earthquake the main finding is that building level damage significantly and negatively impacts the probability that a manufacturing plant will survive, with this effect lasting up to seven years after the earthquake. They also find a small temporary increase in productivity following the earthquake consistent with a build back better effect. ${ }^{8}$ Business survival is also looked at by Basker and Miranda (2017) in the aftermath of the Hurricane Katrina, again using an ex-post assessment of damage at the plant location level, and discover that establishments in large chains were more likely to recover from major structural damage and that establishments located close to banks had better recovery rates. Likewise, for Hurricane Katrina, Craioveanu and Terrell (2016) consider the impact of storms on firm survival using a spatial Bayesian analysis to show that firms with less damage and larger firms in general are more likely to survive. ${ }^{9}$

A further, but little researched, mechanism by which natural disasters can impact firms, that we also investigate in our paper, is through international trade. Of the few studies that examine the trade channel, Gassebner et al. (2010) show, in a study of global disasters between 1962 and 2004, that an additional disaster reduces imports and exports by $0.2 \%$ and $0.1 \%$ respectively. In contrast, Parsons (2016) shows that Hurricane Katrina had no noticeable effect on US imports. Finally, in a detailed study of the impact on Japanese trade following the Great East Japan earthquake of 2011, Ando and Kimura (2012) find a fairly dramatic short-term decline in exports while at the same time imports increased substantially.

\footnotetext{
${ }^{7}$ In a related paper that uses a post-disaster field study following the Sri Lanka tsunami De Mel et al. (2012) show that aid helped retailers to recover but not manufacturing firms. In a study of Vietnam using province level data $\mathrm{Vu}$ and Noy (2018) also investigate how disasters affect firms' retail sales. For a detailed study of the impact of disasters on labor market outcomes see Kirchberger (2017).

${ }^{8}$ Also for the Kobe earthquake, Tanaka (2015) finds a short term negative impact on employment and value added although they assume that all firms in given parts of the city were equally damaged.

${ }^{9}$ In other studies of Hurricane Katrina, Groen et al. (2017) use geo-coded damage data from wind and floods to capture the impact of damage heterogeneity on employment and earnings and LeSage et al. (2011) take a spatial probit approach and find spatial dependence behind the decision of businesses to reopen.
} 
Finally, there is a small literature that considers the impact of natural disasters on supply chains that we address in this paper through our calculation of a number of spatial spillover indices. Theoretically, Henriet et al. (2012) show how a firm's "connectedness" and its ability to find new customers and clients as well as the role of imports to replace domestic suppliers can either dampen or magnify the effect of a natural disaster. One of the first studies in this literature was by Altay and Ramirez (2010) who demonstrate that disasters impact all sectors within the supply chain and that the impact on turnover is dependent on a firm's position within that chain. More recently, Hamaguchi (2013) in a study of manufacturing establishments in the prefectures affected by the Great East Japan earthquake finds that establishments did change parts suppliers (without a loss in product quality but with an increase in cost and distance). Similarly, Inoue and Todo (2017) in a study of Japanese firm supply chains discover that firms tend to substitute damaged for undamaged suppliers and that the size of any direct impact of damage differs greatly depending on the structure of the supply network in an economy. Finally, Hayakawa et al. (2015) show that the 2011 floods in Thailand affected Japanese owned affiliates in Thailand. Although the overall effect was small, firms reduced their local procurement from other Japanese affiliates in Thailand and imports increased from China and Japan (for old and young firms respectively).

To briefly summarize our results, we show that the impact of typhoon damage on firm performance is considerable, resulting in a fall in turnover and profits, although the effect is relatively short-lived, lasting no longer than a year after the shock. Annual total costs to Chinese plants from typhoons are estimated to be in the region of US $\$ 3.2$ billion (2017 prices), or about 1 per cent of average turnover. While the impact can be sizable if a storm is large, our results suggest that the economic impact can be mitigated by plants drawing down on their inventories and through the use of debt instruments and a reduction in existing cash balances. We also find that on average, plants reduce sales to the domestic market to a greater extent than they do to foreign markets and increase their imports of intermediates a year after the storm following a small fall in the year of the storm. Exports in contrast grow considerably in the year after the storm perhaps as a result of damage to local buyers. In terms of labor market outcomes, we also find a small increase in employment in the year after the storm and a reduction in the total value of wages paid in the year of the storm. Finally, we find indirect effects through damages to customers, and competitors, where the largest negative impact is via damage to local domestic customers.

The remainder of the paper is organized as follows. In Section 2 we describe our data, the construction of our plant level panel and our baseline estimating equation. In Section 3 we present our econometric results. We construct and allow for spatial spillovers in Section 4. The final section provides some concluding remarks and discusses the policy implications. 


\section{Data and Methodology}

\subsection{Geographic Region}

We focus our analysis on the effect of typhoons on plants located in China although the plants that are most likely to be damaged are those geographically located in the coastal areas. Although we could have restricted our sample to coastal plants, for completeness we took the data intensive decision to include all plants to ensure that we captured all possible typhoon damage. ${ }^{10}$ Not surprisingly, the major coastal cities tend to be in the most economically important provinces and include Shanghai, Tianjin, Guangzhou, Dalian (Liaoning province), Qingdao (Shandong province), Hangzhou (Zhejiang province) and Xiamen (Fujian province).

\subsection{Plant Level Data}

The plant level data is from the Chinese Annual Survey of Industrial Firms database (CASIF) released by the National Bureau of Statistics (NBS) of China for the period 2000-2006. We restrict our sample to those plants that are active within a 4-digit manufacturing industry code (GB T4754-2002) (corresponding to standard industry classification codes SIC-1310 to SIC-4229) and where the number of employees is greater than eight. ${ }^{11}$ By combining plant name, 6-digit administration code and 4-digit industry code, we are able to generate a unique firm ID for each plant across our sample period that also allows us to follow plants over time. ${ }^{12}$ The CASIF includes a number of firm level variables relevant for our analysis, including turnover, inventories, liquidity ratio, debt ratio, fixed assets, number of employees, total wages, intermediate inputs and profits. In addition, we estimate total factor productivity (TFP) following Levinsohn and Petrin (2003), which takes account of the potential endogeneity of inputs. Finally, we merge the CASIF with Product-level Transaction Data (GACC) to obtain information on plant level imports and exports following the matching process outlined in Liu (2016). All monetary values are deflated to 1998 prices using 4-digit sector deflators (see e.g., Brandt et al. (2014, 2017) for details of the deflation process). To generate our local spillover variables, we use a 2002 input-output table for China. ${ }^{13}$ Definitions and sources for all plant level variables are provided in Table A1 in the Appendix.

\footnotetext{
${ }^{10}$ Typhoons lose speed and destructive power fairly quickly once they make landfall due to the roughness of the surface and the loss of the warm ocean water that fuels them. In previous research Polyzos and Tsiotas, (2012) suggest a $40 \mathrm{~km}$ wide zone in a study of Greece, Elliott et al. (2015) use a buffer of 50km in a previous study of China and Nicolls et al. (2006) use 100km (and an elevation of 100m). Strobl (2011) shows in a US study that tropical storms have no effect on counties that lie inland from the coast.

${ }^{11}$ We follow Brandt et al. (2012), Upward et al. (2013) and Brandt et al. (2017) in using this cut-off since the few firms below this threshold fall under a different regime of self-employed firms, which are generally not covered by the CASIF.

${ }^{12}$ For each Administrative Region (SAR), the third and fourth digits are associated with the prefecture (Diqu in Pinyin), autonomous prefecture, Mongolian league, municipal city district or county. The fifth and sixth digits represent the county level divisions which are city districts, county-level cities and the banner areas of Inner Mongolia. The final two-digits represent the street block level.

${ }^{13}$ The IO tables consist of 122 sectors that are equivalent to 3 -digit Chinese Industrial Classification (CIC) level. We follow Brandt et al. (2012) and link each 4-digit CIC code to an IO sector.
} 


\subsubsection{Geo-Location of Plants}

A critical task for our analysis is to determine the exact geo-location of plants. To do this we use information on the address of each plant for the first year that they are in the data. This gives us a unique geo-location (longitude and latitude) for each year for around $55 \%$ of our plants. The remaining $45 \%$ of plants share an address. ${ }^{14}$ For plants where the address information was missing we used an internet search to find the address and these plants were subsequently included in our sample. ${ }^{15}$ All remaining plants for which we could not find sufficient information were dropped. One complicating factor is that plants may relocate within our study period. This is further complicated by poor address information for some of the earlier years of our sample which may make it appear, incorrectly, that a plant has moved. ${ }^{16}$ To prevent any possible miss-classification we used data for those years with higher quality data (2000, 2003, 2004 and 2006) and calculated the Euclidean distance to the address of the other years for any given plant such that if the distance was within $1 \mathrm{~km}$ we assumed there was no change of address. Our results reveal that there were 60,357 plant moves within our sample where a mover is classified as those with more than one geo-location during our time period $(6.5 \%$ of the total number of observations of 932,723$)$.

After geo-locating plants and excluding any observations where we were unable to construct all of our performance indicators our final sample of plants consists of 251,828 unique plants over 186,618 unique locations meaning that we dropped approximately $2 \%$ of plants. For our study period 2000-2006, the locations of the plants in our sample are shown in Figure 1. As can be seen, plants are disproportionately located along the coast. One may want to note in this regard that this distribution pattern also coincides with the distribution of population within China.

\subsection{Plant Level Typhoon Damages}

The damage caused by a typhoon depends mainly on three related aspects: wind-speed, flooding/excess rainfall, and storm surge. A simplifying, and commonly adopted assumption in the literature is that the latter two effects, which are much more difficult to model, are highly correlated with wind speed and thus one can use wind speed as a proxy for the potential damage due to a typhoon strike. ${ }^{17}$ Here we also adopt this convention.

\footnotetext{
${ }^{14}$ Plants may share an address if, for example, they are located in a newly established industrial park that has a temporary land-use code and name, or if the address is a village without detailed road names or door numbers. The largest number of replications that we keep in our sample is 50. In cases where the number is over 50 we use manual internet searches to obtain more accurate address information and accounts for 23,949 observations and 8,703 plants across our time period.

${ }^{15}$ In each case we referenced the address with the administration code and postcode provided in the CASIF to confirm the address found on the websites.

${ }^{16}$ Some address information in the earlier years only included a general county name and lacked more detailed village or street information.

${ }^{17}$ See Emanuel (2011) for a more detailed discussion on the relationship between wind speed and flooding/storm surge.
} 


\subsubsection{Typhoon Tracks}

To model typhoon damage we use storm tracks from the Regional Specialized Meteorological Centre (RSMC) which provides six hourly (i.e. every six hours) data on all tropical cyclones that formed in the West Pacific since 1951. The information available includes the position of the eye of the storm and the maximum wind speed during a storm's lifetime. We linearly interpolate the six-hourly data into hourly estimates for each longitude and latitude along the Chinese coast. We also restrict the set of storms to those that came within $500 \mathrm{~km}$ of the coast of China (since tropical cyclones generally do not exceed a diameter of 1,000 km) and that at some stage during their lifetime achieved at least typhoon strength. Figure 1 shows the tracks of typhoons and other tropical storms that formed in and around the Chinese coast between 1998 and 2006. The solid red lines represent the segment of the storm when it reached typhoon strength and would have caused the greatest damage. ${ }^{18}$

Our wind field model is calculated for the period 1998 to 2006 using the typhoon track data described above. A total of 58 damaging storms struck China during this period and 45 between 2000 and 2006 (the storms, their maximum wind speed and damage estimates are provided in Table A2).

\subsubsection{Local Typhoon Wind Speed}

An important factor when it comes to measuring the damage to an individual plant is the wind speed that a plant experiences during a typhoon and will depend on the exact location of the plant relative to the movement and features of the storm. To model this we apply the Boose, Serrano, and Foster (2004) version of the well-known Holland (1980) wind field model, according to which the approximate local wind speed at any point $i$, for storm $k$, in time $t$ is given by:

$$
v_{i k t}=G F\left[V_{\text {max }, k t}-S\left(1-S I N\left(T_{i k t}\right)\right) \frac{V_{h, k t}}{2}\right]\left[\left(\frac{R_{\max , k, t}}{R_{i t}}\right)^{B_{k t}} \exp \left(1-\left[\frac{R_{\max , k, t}}{R_{i t}}\right] B_{k t}\right)\right]^{\frac{1}{2}}
$$

where $V_{\max }$ is the maximum sustained wind velocity anywhere in the typhoon, $T$ is the clockwise angle between the forward path of the typhoon and a radial line from the typhoon center to the point of interest $i, V_{h}$ is the forward velocity of the tropical storm, $R_{\max }$ is the radius of maximum winds and $R$ is the radial distance from the center of the tropical storm to point $i, G$ the gust factor, and $F, S$, and $B$ are the scaling factors for surface friction, asymmetry due to the forward motion of the storm, and the shape of the wind profile curve, respectively.

In terms of implementing equation (1) the maximum wind speed $V M A X$ is taken from the RSMC, $V_{h}$ can be calculated following the movement path of the storm, while $R$ and $T$ can be determined by using the relative position between the eye of the typhoon and our

\footnotetext{
${ }^{18}$ Although our plant level data is from 2000-2006 we include storms from 1998 to allows us to include a small number of lags.
} 
point of interest $i$. We set $G$ equal to 1.5 and $S$ equal to 1 following Paulsen and Schroeder (2005) and Boose et al. (2004), respectively. For the surface friction indicator $F$, Vickery et al. (2009) suggest that in open water the reduction factor is around 0.7 and a reduction in wind-speed of around $14 \%$ on the coast and $28 \% 50 \mathrm{~km}$ inland. Following Elliott et al. (2015) we linearize the reduction factor to capture the friction effect of the typhoon as it moves inland. In terms of the pressure profile parameter $B$ and the radius maximum winds $R_{\max }$ we adopt Holland (2008)'s approximation method and the parametric model of Xiao et al. (2009).

\subsubsection{Damage Function}

As noted by Emanuel (2011), there are energy dissipation reasons to assume that the relationship between wind speed experienced and damage incurred is to the cubic power. Moreover, there is unlikely to be any damage for winds that fall below $92 \mathrm{~km} / \mathrm{hr}$. Incorporating these features and to ensure that the percentage of damage varies between 0 and 1, Emanuel (2011) proposes the following damage function for wind of storm $k$ experienced at location $i$ :

$$
f_{i k}=\frac{v_{i k}^{3}}{1+v_{i k}^{3}}
$$

where

$$
v_{i k}=\frac{M A X\left[\left(v_{i k}-v_{\text {thresh }}\right), 0\right]}{v_{\text {half }}-v_{\text {thresh }}}
$$

where $v_{i k}$ is the maximum wind speed of storm $k$ experienced at point of interest $i, v_{t h r e s h}$ is the threshold below which no damage occurs, and $v_{\text {half }}$ is the threshold at which half of the property is damaged. Following Emanuel (2011) we assume values of $92 \mathrm{~km} / \mathrm{h}$ and 204 $\mathrm{km} / \mathrm{h}$ for $v_{\text {thresh }}$ and $v_{\text {half }}$, respectively.

Note that equation (1) is defined in terms of the percentage of damage caused per storm. Given that our plant data is annual, any given plant could feasibly be hit by several storms in a year. Hence, to account for the possibility of multiple strikes we assume that damages can accumulate over a year, but restrict the impact of additional storms to have less than a simple cumulative effect. Rather, under the assumption that weak and fragile structures get destroyed first, leaving more resistant structures, we allow damage to be multiplicative for storms $k=1, \ldots, K$ within a year $t$ as follows:

$$
f_{i t}=\sum_{k=1}^{K} \prod_{i=1}^{k} f_{i k}
$$

\subsection{Nightlight Intensity}

In order to proxy economic activity at the local level we follow a large literature, such as Henderson et al. (2012), and use data derived from satellite images of nightlights. More specifically, we use nightlight imagery provided by the Defense Meteorological Satellite Program (DMSP) satellites. In terms of coverage each DMSP satellite has a 101 minute near- 
polar orbit at an altitude of about $800 \mathrm{~km}$ above the surface of the earth, providing global coverage twice per day, at the same local time each day at about the $1 \mathrm{~km}$ resolution.

\subsection{Climatic Controls}

Auffhammer et al. (2013) demonstrate that different climatic phenomenon can impact economic activity. Likewise, in a recent paper P. Zhang et al. (2018) examine the impact of temperature changes on the productivity of Chinese plants and find that output could fall by $12 \%$ based on 2050 predictions of climate change under the assumption of no adaptation. High temperatures have also been linked to lower economic activity by Hsiang (2010) and Chen and Yang (2018). Hence, to control for other potentially confounding factors we construct localized measures of rainfall and temperature to include as additional controls in our estimations.

\subsubsection{Rainfall}

To capture local rainfall we use the satellite derived Tropical Rainfall Measuring Mission (TRMM)-adjusted merged-infrared precipitation (3B42 V7) product. These 3 hourly precipitation estimates are generated by first using the TRMM Visible and Infrared Scanner (VIRS) and TMI orbit data (TRMM products 1B01 and 2A12) and the TMI/TRMM Combined Instrument (TCI) calibration parameters (from TRMM product 3B31) to produce IR calibration parameters. The derived IR calibration parameters are then employed to adjust the merged-IR precipitation data, which consists of GMS, Geostationary Operational Environmental Satellites (GOES-E and GOES-W), Meteosat-7, Meteosat-5, and NOAA-12 data. The final gridded, adjusted merged-IR precipitation $(\mathrm{mm} / \mathrm{hr})$, data have a 3 hourly temporal resolution and a 0.25-degree by 0.25-degree spatial resolution and extend from 50 degrees south to 50 degrees north latitude. They are available from 1998. Matching each plant to the nearest centroid of the TRMM grid cells we calculate its yearly mean daily rainfall.

\subsubsection{Temperature}

To construct yearly mean daily temperature for each plant we take data from the National Climatic Data Center (NCDC) at the National Oceanic and Atmospheric Administration (NOAA), which provides daily data for several hundred weather stations across China. When we use the temperature observations to spatially interpolate values to the location of plants there are two potentially important factors that we need to consider. First, temperature can vary considerably with changes in elevation. A common solution is to estimate lapse rates between stations, which mean estimating the relationship between temperature and elevation and then spatially interpolating temperature according to suggested variation in temperature with changes in altitude. ${ }^{19} \mathrm{~A}$ second potentially pertinent feature of spatial variation in temperature is that temperature is likely be higher in urbanized areas due to human activity, also known as the urban island heat effect. To incorporate these two aspects into our spatial interpolation we follow Li et al. (2013) and specify a lapse rate equation, but control for the urban island heat effect via:

\footnotetext{
${ }^{19}$ For applications related to China see Fang and Yoda (1988) and Tang and Fang (2006).
} 


$$
\begin{aligned}
& \text { temperature }_{w n t}=\alpha+\beta_{1} \text { latitude }_{w}+\beta_{2} \text { longitude }_{w}+\beta_{3} \text { altitude }_{w}+\beta_{4} \text { heatisland }_{w t}+ \\
& \beta_{5} \text { heatisland }_{w t} \times \text { altitude }_{w}+\epsilon_{w n t}
\end{aligned}
$$

where subscripts $w, m$, and $t$ stand for weather station $w$, month $n$, and year $t$, temperature is the average daily temperature at station $w$, in year $t$, in month $n$, latitude, longitude, and altitude are the geographic coordinates and altitude of the station, respectively, and heatisland is our proxy for urban heat islands, the effect of which we also allow to vary with altitude. To measure elevation we use the digital elevation model from the Shuttle Radar Topography Mission, which has a resolution of $90 \mathrm{~m}$, and assume a station's altitude to be the value of the cell closest to it. To proxy the urban heat island effect, we follow Chen and Nordhaus (2011) and Henderson et al. (2012) and use information from the DMSP satellite, which has provided normalized annual nightlight intensity (between 0 and 63) at roughly $1 \mathrm{~km}$ grid cell level size since 1992. More specifically, for each weather station for each year we take the pixel value whose centroid is closest to the station, and, following Yang et al. (2014), we set this equal to its given value if the value is at least 12, and zero otherwise.

In order to be able to implement equation (4) we keep only those months of data for a station which had no more than one day of temperature missing and for which we had a complete series over the period 1992-2006. This leaves us with data for 365 stations. Equation (4) was then estimated for individual months since the lapse rate has been shown to vary substantially across seasons (Li et al., 2013). The estimated lapse rate was found to be on average around -0.0043, suggesting a fall in temperature of 4.3 degrees for a rise in altitude of $1000 \mathrm{~m}$, which lies well within the range found for China (see e.g. Li et al. (2013)). The coefficient on heatisland was positive and significant and that on heatisland $\times$ altitude was negative and significant, indicating the existence of a heat island effect but that the effect was lower at higher altitudes. The estimated parameters were then used in conjunction with the altitude and local level of urban agglomeration (i.e., the value of local nightlight intensity) of stations and plants to generate daily temperature by month for each plant. More specifically, for every plant we identified the temperature value of the weather stations located within $200 \mathrm{~km}$ of the plant, calculated the difference in altitude and heat island between each of these stations and the plant, predicted the average daily temperature suggested by estimates of equation (4), created the distance weighted average across all stations within the $200 \mathrm{~km}$ vicinity, and then averaged resultant monthly series into annual average daily degrees. ${ }^{20}$

\subsection{Summary Statistics}

Table 1 provides summary statistics for our sample for the main variables we use in our regression analysis. As can be seen, turnover varies considerably across plants, ranging from RMB 800 to RMB $167,145,800,000$ with a mean of RMB 72,000,000. One may want to note that of the 251,828 unique plant in our final data set, $30.53 \%$ experienced some damage from a typhoon at least once during the period of our study, and that the level of damage for

\footnotetext{
${ }^{20}$ We linearly interpolated nightlight intensity values between years to generate monthly values. Results from the estimation of equation (4) are available upon request.
} 
these incidences was 4 per cent, but with considerable variation. This is further attested to in the histogram of non-zero values ${ }^{21}$ of $f$ (which constitute $16.4 \%$ of the sample), shown in Figure 2, where the distribution is characterized by a fat tail, as is common with extreme weather events. In terms of our other variables one can see that plants have on average a debt equal to 59 per cent of their annual turnover. Also, about 11 per cent of turnover is exported, while about 90 per cent of inputs are sourced locally, in that they purchased from local rather than foreign suppliers.

\subsection{Baseline Regression}

Our benchmark specification to investigate the impact of typhoon strikes on Chinese manufacturing plants is given by:

$$
Y_{i t}=\alpha+\sum_{l=0}^{L} \beta_{f l} f_{i t-l}+\sum_{l=0}^{L} \beta_{C l} C_{i t-l}+\pi_{t}+\operatorname{Trend}_{D}+\mu_{i}+\epsilon_{i t}
$$

where $Y$ is our dependent variable of interest for plant $i$ at time $t$. One should note that since many of the dependent variables we experiment with have a non-negligible amount of zeros and are fat (right) tailed distributed, we, as suggested by Burbidge, Magee, and Robb (1988), use an inverse hyperbolic sine transformation to take account of this. Thus coefficients on our explanatory variables can be interpreted as in log-level equations. $f$ is our damage index, potentially lagged $l$ times, $C$ our climatic controls (average daily temperature and rainfall), and $\epsilon$ the error term. Time dummies $\pi_{t}$ are included to account for time varying effects common to all plants. We take account of time invariant plant specific unobservables, $\mu_{i}$, by using a fixed effects estimator. Trend $d_{D}$ are geographic $D$ specific time trends, where we divide China into a regional grid according to each 1 degree of longitude and each 0.1 degree of latitude (resulting in a total of 138 grids). ${ }^{22}$ In order to allow for serial and spatial correlation we calculate Driscoll and Kraay (1998) standard errors.

Arguably, our coefficients of interest, namely the contemporaneous and lagged effects of typhoon damage, $\beta_{f l}$, are unbiased from an economic decision-making perspective. More specifically, plant fixed effects will control for any time invariant firm and location specific factors that may be related to typhoon exposure. The relatively high spatial resolution of the geographic specific time trends, on the other hand, will likely capture any firm specific trends related to local trends in typhoon occurrence. Our climatic controls capture any other confounding factors that might be correlated with typhoons (Auffhammer et al., 2013). Therefore, $f$ will, after all of these controls, arguably simply be random realizations drawn from the local typhoon damage distribution. One may want to note that our specification above includes essentially no time varying plant specific controls. This is because all plant

\footnotetext{
21

${ }^{22}$ Making the grid vary more across latitude rather than longitude was done because (i) our large sample limited the number of locality specific time trends we could include in the estimation, and (ii) for China typhoons vary much more in latitude rather than longitude, since friction on land reduces their strength considerably.
} 
level variables we have could arguably be affected by typhoon damage, and thus would potentially constitute "bad regressors" (Angrist and Pischke (2009)).

\section{Results}

\subsection{Turnover}

Table 2 presents the results for the impact of a typhoon on plant turnover for our sample of manufacturing plants from estimating equation (5). In the first three columns we show the results without any climatic controls and systematically including a greater number of lags of $f$. As can be seen, typhoon damage reduces an affected plant's turnover, but only in the year of the strike. In Columns (4) through (6) we do the same exercise but this time include climatic controls and their appropriately lagged values to coincide with the number of lags of $f$. Accordingly, we still only find a contemporaneous effect of typhoon damage on plant turnover, but this effect is $22 \%$ smaller. Thus, not controlling for potentially confounding climatic variables other than the typhoon by itself may result in an upward downward bias in the estimated damage effect of typhoons on plant turnover.

Using the estimate on $f$ in the fourth column as our benchmark specification the implied coefficient suggests that when an average damaging typhoon (3.7\% damage) occurs, Chinese manufacturing plants experience around a 1 per cent reduction in turnover. If we consider the largest plant specific value of typhoon damage observed in our data set (75.5\%), this would have caused a 19 per cent reduction in output. If we take the total damages experienced by Chinese plants due to typhoons over our seven-year period, our results imply that on average annual turnover was reduced by 21.4 billion RMB, or 3.2 billion US\$ (in 2017 prices). ${ }^{23}$

\subsection{Robustness Checks}

We also conduct a number of robustness checks. One concern may be that our findings are driven by a single storm. To investigate this we systematically took each of the 58 storms, and set the damages for this storm to zero, and then re-estimated the impact on turnover of this new $f$ the same as the specification of Column (4) in Table 2. The estimated coefficient on $f_{t}$ ranged from -0.183 to -0.160 . Importantly, all of these coefficients were highly significant, where the $t$-statistic ranged from -18.8 to -8.0 .

In a second robustness check we implemented a Fisher type randomization test, where we randomly reshuffled the years in our panel data, breaking the temporal link between damages and turnover. This allows us to compute the probability of observing our significant estimates compared to randomly assigning years. A histogram of the estimated t-statistic for $f_{t}$ is shown in Figure 3. As can be seen, compared to the distribution the significance on these coefficients the $t$-statistic on our estimated coefficient of $f$, shown by the red vertical

\footnotetext{
${ }^{23}$ To illustrate how we calculated our economic values, the $\%$ reduction in turnover $=[$ mean of $\mathrm{f}$ index $(\mathrm{f}>0) *$ coefficient from column 4 of Table 2$] /$ mean of turnover (only for obs with $\mathrm{f}>0)=[3.7 \% *(-0.167)] /$ $66.95266=0.92289089 \%=$ approximately $1 \%$.
} 
line, is unlikely to be random. As a matter of fact, the permutation p-value is 0.005 .

One concerns may be that feasibly outliers could be driving our results, as the largest value of turnover in our data is more than 4 standard deviations above the mean. To explore this further we excluded observations above and below the $95^{\text {th }}$ and $99^{\text {th }}$ percentile of the turnover distribution. This produced (statistically significant at the $1 \%$ level) coefficients of -0.183 and -0.165 , respectively. We additionally calculated Cooke's standardized residuals from our main specification with the full sample and re-ran it excluding those observations whose residual was greater than $4 / \mathrm{N}$, where $\mathrm{N}$ is the total number of observations (see Cook (2000)). Again, the corresponding coefficient on $f_{t}$ remained statistically significant at the $1 \%$ level and fairly close in value $(-0.138)$ to the coefficient from the total sample $(-0.167)$.

We also conducted a placebo test where we assumed that the typhoon damages occurred a year earlier than their actual occurrence. The results of this are shown in Column (7)

of Table 2. Accordingly, there is, somewhat surprisingly, a marginally significant positive effect. One reason may be that we are including an additional storm year of data (2007) and ignoring a storm year (2000) in order to preserve our sample size. As a matter of fact, examining the distribution of non-zero values of $f_{t+1}$ in Figure 4 one may want to note that 2007 was a particularly inactive and 2000 a particularly active year, and thus shifts the distribution somewhat to lower values of $f$ compared to Figure 2, In view of this, to examine how robust the significant effect on $f_{t+1}$ is we conducted a Fisher type randomization test as above, randomly reshuffling the years in our data. The histogram of the resultant t-statistics, shown in Figure 5, and the permutation p-value of 0.288, however, suggest that we cannot rule out the possibility that the positive impact is likely random rather than causal.

The reason that we excluded other plant specific control variable available form our data set thus far, apart from plant specific and time fixed effects, regional time trends, and climatic controls, is that these could potentially constitute 'bad controls' if they were affected by typhoons themselves. To circumvent this problem we estimated our main specification with lagged employment as an additional control, as shown in the final column Table 2. However, as can be seen doing so has little effect on the estimates of $f$.

A final concern may be that plants that drop out of our sample, either because they shut down operation or become too small could be driving our results. To indirectly investigate this we investigated whether a plant dropping out of our sample could be predicted by typhoon damage by running a linear probability model, including all controls from our main specification. The coefficient (-0.093) was, however, insignificant.

\subsection{Financial Health and Labor Market Outcomes}

In Columns (1) to (3) of Table 3 we investigate the implications of a drop in turnover due to typhoon damage shown in Table 2 for a plant's financial health, by replacing the dependent variable in equation (5) with, alternatively, a plant's profits, debt ratio and liquidity ratio. Since for none of these, or any of other dependent variables that we subsequently use, there 
was an effect beyond $t-1$, we simply report the results including only up to a $t-1$ lag. Column (1) shows that total profits fall only in the year after the typhoon strike that translates into about 3 per cent for an average storm. In contrast, we can see an immediate negative effect on TFP, as shown in Column (2), although one may want to note that the reduction is marginal, where for the average plant productivity for the average damaging storm falls by just 0.14 per cent.

In terms of our financial health variables, we find that liquidity decreases for up to one year after a damaging typhoon (shown in Columns (3)), with roughly similar falls at $t$ and $t-1$. At the same time plants increase their debt for up to a year after the storm as shown in Column (4). Reducing liquidity and increasing debt can both be considered as forms of buffering in the event of a negative external shock with funds (either borrowed or spent from resources) being used to try and ensure that the business bounces back as quickly as possible and is able to carry on with business as usual.

In Columns (5) and (6) we investigate the effect of typhoon damage on labor market outcomes, namely the average wage and employment levels. Our results show that plants have a lower total wage bill in the year that the typhoon strikes, but that there is no immediate effect on employment. A year later wages have returned to their pre-storm level, but employment has temporarily increased. This employment effect may be because storm damaged plants become more labor intensive as a result of damage to their capital such that labour is substituted for capital (Coelli \& Manasse, 2014). A fear that workers may leave a damaged plant to find alternative work appears unfounded or if they do replacement workers are hired within the same year. In terms of wages, the initial fall in wages in the year of the strike may be a result of substitution of highly paid workers for lower paid workers leading to a fall in total wages paid or alternatively that a plant stops paying wages when a factory temporarily shuts down hence reduces total wages for the year but not the number of employees (if for example the factory pays piece rates). Taking the significant coefficient on lagged employment at face value the results suggest that for average typhoon damages there were an additional 2 workers hired per plant (or a 0.8 per cent increase), while maximum observed damage implies hiring an extra 38 employees.

\subsection{Inventories and Internationalization}

In Table 4 we investigate other channels by which a plant may adjust to reduced output. Column (1) of Table 4 considers whether plants draw down on previously produced, but not yet sold output, i.e. inventories, to meet consumer demand as a means of mitigating the direct impact from lost output due to lost production capacity. As can be seen, there is an immediate negative impact on inventories followed by a positive impact at $t-1$, suggesting that the fall in profits in the year after the strike may not only be due to a fall in production but in a rise in unsold output, which shows up in the following years inventory or simply that the firm is making a conscious effort to rebuild inventories. Quantitatively, the estimate suggest that inventories for the average (maximum) observed damages in our sample inventory would in that year have fallen by 1 (21) per cent. When we examine the expenditure on intermediate inputs, Column (2) shows that there is no significantly negative impact on 
the purchase of intermediate inputs due to typhoon damage.

Given China's close association with global supply chains it is useful to understand how natural disasters can impact patterns of internationalization. More precisely, given that about a fifth of the plants in our sample export, it is of interest to see whether, in the face of a production shock, plants reduce sales to foreign buyers more or less than to domestic buyers. More precisely, we break down the production into that which is exported and output that is sold domestically, the results of which are shown in Columns (3) and (4). Our results show that domestic sales fall only in the year of the strike (matching the total turnover results), where the quantitative effect is somewhat larger than the latter (for the equivalent specification for Turnover in Table 2 the coefficient was -0.117). ${ }^{24}$ In contrast, while total exports also fall in the year of the strike they do so by a smaller amount. ${ }^{25}$ Moreover, exports increase the year after the strike by an amount that is a multiple of the drop in exports at $t$. This result suggests that as plants recovery they target overseas markets perhaps as a result of a reduced demand from domestic buyers some of which may have been damaged by the typhoon, because customers were lost to undamaged competitors, or as part of a strategy to hedge the risk against future strikes.

In a similar spirit to the role of exporting, we examine whether, when facing a fall in production due to the typhoons, plants are more likely to reduce their purchase of foreign or domestic inputs. As can be seen from Columns (5) and (6), there is a small negative impact on imported inputs in $t$ and a similar but much smaller increase than that of exports in $t-1$. One explanation is that damage to ports or other transport infrastructure may reduce imports in the short term and delivery is delayed until the following year. In contrast, plants, when damaged by a typhoon, tend to maintain their domestically sourced inputs in both time periods. The significantly estimated coefficient suggests that for an average storm the immediate effect on imports and exports is relatively small, though, only about a half of a percentage point as plants presumably attempt to maintain their international networks and partnerships.

\section{Spatial Spillover Effects}

\subsection{Spatial spillover variables}

Plants may not only be affected directly by a damaging storm, but also indirectly through damages incurred by the local economy to which they are linked. More specifically, a plant may be impacted by local typhoon damage, irrespective of any damage incurred directly, in three possible ways: (i) if its intermediate suppliers are damaged so that a plant is unable to source some of the inputs needed for the production process, (ii) if the production lines of those plants that a plant normally supplies are damaged and they subsequently reduce their purchase of intermediates, and/or (iii) if other competitors producing the same product have been damaged so that the plant is able to capture part of their market share as customers

\footnotetext{
${ }^{24} \mathrm{~A}$ z-test statistic of the difference was 2.2

${ }^{25} \mathrm{~A} z$-test strongly suggested that these were statistically significantly different.
} 
strive to find alternative sources of supply. To incorporate these local linkages, we calculate three spatial damage spillover proxies based on three different plant distance differences.

To proxy the extent of any spillovers from plants competing in the same local market, for each plant $i$ we first identify the other $j \neq i$ plants operating in the same product sector, $s$, that are located within distance, $m$, of it, i.e., plants $j \neq i$ for which distance $_{i j} \leq m$. We then use their lagged turnover at time $t-1$ relative to the total output of all plants in this sector $s$ within $m$ distance of plant $i$ at time $t-1$ to generated a turnover weighted average typhoon damage index, $\operatorname{OUTPUTSP}(m):{ }^{26}$

$$
\begin{aligned}
& \operatorname{OUTPUTSP}(m)_{i t}=\sum_{j \neq i}^{N_{s}} f_{j, t} \frac{\mathbf{1}_{s} \times \mathbf{1}_{m} \times O U T P U T_{j, t-1}}{\sum_{i}^{N_{s}} \mathbf{1}_{m} \times O U T P U T_{i, t-1}} ; \\
& \mathbf{1}_{m}=\left\{\begin{array}{ll}
1 & \text { distance }_{i j} \leq m \\
0 & \text { distance }_{i j}>m
\end{array} \quad \mathbf{1}_{s}= \begin{cases}1 & s_{j}=s_{i} \\
0 & s_{j} \neq s_{i}\end{cases} \right.
\end{aligned}
$$

where $O U T P U T_{j, t-1}, j \neq i \in N_{s}$, is the turnover of all plants $j$ other than $i$ operating in the same sector $s, \mathbf{1}_{s}$ is an indicator function that takes plant $j$ is in the same sector $s$ as plant $i$, and zero otherwise, and $\mathbf{1}_{s}$ is an indicator function plant plant $j$ is within $m \mathrm{~km}$ of plant $i$, and zero otherwise. In other words, OUTPUTSP $(m)_{i t}$ is the damage ratio of output from all other firms in sector $s$ within distance $m$ of firm $i$, and can vary between 0 and 1 .

To capture typhoon damage to nearby plants that may potentially supply inputs to plant $i$ we first construct the importance of input sectors $r$ to a plant $i$ 's sector $s$ by using information on the share of inputs sourced across sectors from the 2002 input-output table for China, defined as $\frac{I N P U T_{r s}}{I N P U T_{s}}$, where $I N P U T_{s}$ is the total inputs to sector $s$ and INPUTS rs are the inputs into sector $s$ sourced from sector $r$. With this in hand we can then calculate the average (lagged at $t-1$ ) output weighted typhoon destruction index for each of plant $i$ 's input sourcing sectors $r$ within a chosen distance $m$ from the plant:

$$
I N P U T S P(m)_{i t}=\sum_{r=1}^{R} \frac{I N P U T_{r s}}{I N P U T_{s}} \sum_{j \neq i}^{N_{r}} \mathbf{1}_{m} \times f_{j, t} \frac{O U T P U T_{j, t-1}}{\sum_{i}^{N_{r}} \mathbf{1}_{m} \times O U T P U T_{j, t-1}}
$$

$\operatorname{INPUTSP}(m)_{i t}$ is thus the damage ratio of output from all firms within distance $m$ of firm $i$ that operate within sectors $R$ that supply inputs to firms in the same sector as firm $i$, weighted by the average importance of these upstream sectors to sector $s$.

Finally, we also use the 2002 input-output table to proxy the share of supply of inputs from a plant $i$ in sector $s$ to other plants in sectors $k$, i.e., $\frac{S U P P L Y Y_{s k}}{S U P L Y_{s}}$, where $S U P P L Y_{s}$ is the total supply of sector $s$ to other sectors and $S U P P L Y_{s k}$ the supply of sector $s$ to sector $k$. These are then used to proxy the average local (within distance $m$ ) demand for plant $i$ 's output by:

\footnotetext{
${ }^{26}$ We use weights constructed from $t-1$ in order to ensure that these are not affected by the typhoon itself.
} 


$$
S U P P L Y S P(m)_{i t}=\sum_{k=1}^{K} \frac{S U P P L Y_{s k}}{S U P P L Y_{s}} \sum_{j \neq i}^{N_{k}} \mathbf{1}_{m} \times f_{j, k, t} \frac{\operatorname{OUTPUT}_{j, t-1}}{\sum_{i}^{N_{k}} \mathbf{1}_{m} \times \operatorname{OUTPUT}_{j, t-1}}
$$

where $S U P P L Y S P(m)_{i t}$ is the damage ratio of output from all firms within distance $m$ of firm $i$ that operate within sectors $K$ that purchase inputs from firms in the same sector as firm $i$, weighted by the average importance of these downstream sectors to sector $s$.

\subsection{Spillover Regression}

We incorporate our spillover variables for our base specification as follows:

$$
\begin{aligned}
& Y_{i t}=\alpha+\beta_{f} f_{i t}+\beta_{\text {OUTPUTSP }(m)} \operatorname{OUTPUTSP}(m)_{i t}+\beta_{\text {INPUTSP }(m)} \operatorname{INPUTSP}(m)_{i t} \\
& +\beta_{S U P P L Y S P(m)} S U P P L Y S P(m)_{i t}+\beta_{N L(m)} N L(m)_{i t}+\beta_{C} C_{i t}+\pi_{t}+\operatorname{Trend}_{D}+\mu_{i}+\epsilon_{i t} ; \\
& m=1, \ldots, M
\end{aligned}
$$

One should note that to estimate the role of spillovers on the impact of typhoon destruction with the indices above we necessarily need to exclude the year 2000, since we need lagged turnover to weight plants for the three spillover variables. ${ }^{27}$ In order to control for local agglomeration economies we also include lagged values of nightlight intensity, $N L(m)$, adjusted to coincide with the chosen distance $m$ of our spillover variables.

A priori we have no reason to prefer any particular cutoff distance $M$ and thus begin with using $m=1 \mathrm{~km}$ and then systematically increasing it up to $200 \mathrm{~km}$, after which the construction of spillover variables became too computationally intensive. Importantly, one should also note that our spillover variables could only be defined in terms of the plants in the data set. To limit this as much as possible, we included all plants that had non-missing turnover to construct our indices regardless of whether they were included in the regressions or not. Nevertheless, it must be acknowledged that we are still missing plants that fall below the inclusion threshold.

\subsection{Results}

Our results for the coefficients on the three spillover variables as well as on $f$ are shown in Figure 6. As can be seen from panel (a), the coefficient on the typhoon damage index remains significant no matter what cut-off distance we set for our spillover variables, only decreasing slightly. Thus the significant impact of plant's own damage on turnover is not actually solely driven by spillovers from other nearby plants. Examining the competition spillover variable, OUTPUTSP $(m)$, in panel (b), one finds that there is a small positive impact on a plant's turnover if other plants it competes with suffer typhoon damage, although this is limited to

\footnotetext{
${ }^{27}$ Excluding the year 2000 produced a reassuringly statistically significant coefficient of -0.166 on $f$ for the equivalent regression in Column (4) of Table 2.
} 
just a few kilometers. Somewhat surprisingly there is a negative impact on turnover if one considers damage to plants in the same sector that are located within 38 and $65 \mathrm{~km}$. One possibility is that this is capturing damage to transportation infrastructure used by nearby plants in the same sector. While we are unable to test this directly, we did calculate out the distance between plants and their nearest mode of transport, measured as either highway or port, and indeed found this to be on average around $48 \mathrm{~km}$.

In terms of spillovers effects via damage to plants operating nearby in the typical input sectors, INPUTSP $(m)$, except for a somewhat peculiar very small positive impact when input supplying firms are in close proximity, we find no significant impact until from around $140 \mathrm{~km}$ onwards. Thus it appears that firms may be generally relying on inputs from firms relatively far away, and experience a negative turnover shock, likely due to input shortages, when these are damaged. The negative impact that firms experience when firms they typically supply to are damaged occurs at a closer proximity, starting from $76 \mathrm{~km}$ onwards and rising steadily as we increase the cutoff distance $m$. More generally our results tentatively suggest that Chinese manufacturing firms turnover may be affected indirectly by typhoons if these storms affect downstream and upstream firms, even if these are located far away.

\section{Conclusions}

In this paper we use the exact location of establishments and a physical typhoon wind field model to quantify the impact of typhoon damages on various aspects of performance for a panel of Chinese manufacturing plants many of which are located in China's coastal regions. In one of the first studies of its type, our general finding is that the impact on plant's can be large but is relatively short-lived. For example, the average damaging storm is likely to reduce a plant's turnover by 1 per cent the year of the strike. If we consider our sample period, 2000 to 2006, our estimations suggest that turnover for Chinese manufacturing plants fell by around 3.7 percent due to typhoon activity. These are damages that can be considered over and above the direct costs due to infrastructure and property damage. The total damage is therefore estimated to be in the region of US3.2 billion per year or over US $\$ 21$ billion over the seven years of our sample (in 2017 prices).

By investigating the channels by which plants respond to typhoon damage we are able to show that plants are able to partially temporarily buffer these negative shocks by reducing inventories, taking on additional or new debt, and reducing their liquidity. There is also a preference to buffer typhoon damages through foreign markets in terms of sales, while imports and exports show increases in the year after the storm. Moreover, our analysis indicates that plants are also indirectly affected by damages to plants that they compete with and are supplied from, although this depends on how one spatially restricts these spillovers. The main negative impact is through domestic suppliers of intermediate inputs and may explain the increase in imports to compensate.

Our findings arguably have important policy implications. Although the number of newly established manufacturing plants in the hinterland of China is growing, China's coastal 
regions still remain the center of manufacturing activity. Given the potential for an increase in the frequency and/or intensity of future tropical cyclones it is important for the Chinese government to understand the potential damage to plants and how to mitigate these future losses. One should note in this regard that disaster relief in China tends to be fairly rapid with local government agencies offering funds and loans to help rebuild damaged infrastructure. This could be one reason that we do not find any long-term effects on plants in China, although a lack of data has not allowed us to investigate this further. Nevertheless, in 2017 China published the "Report on the Development of Urban Public Safety in China, 2016-2017" that emphasized the further need for natural disaster prevention and mitigation in urban areas. In this regard a central pillar of any policy to build resilience to natural disasters is the establishment of a standing natural disaster reaction department working together with related academic and research institutes to provide information on disaster forecasting, prevention, mitigation and resilience at different stages of any emergency. It is also important for China to establish a comprehensive insurance market, which does note yet exist, to help reduce the financial burden on the central government. For example, in 2001, only $5 \%$ of commercial and industrial property was insured J. Wang (2010). Other possible mitigation provincial governments could take include improved sea defenses, the building and maintenance of urban drainage systems and the provision of emergency shelters (Chengcheng et al., 2014) all of which will help plants to become more resilient to future shocks. 


\section{Figures}

Figure 1: The Geographic Distribution of Manufacturing Plants in China (Regression Sample)

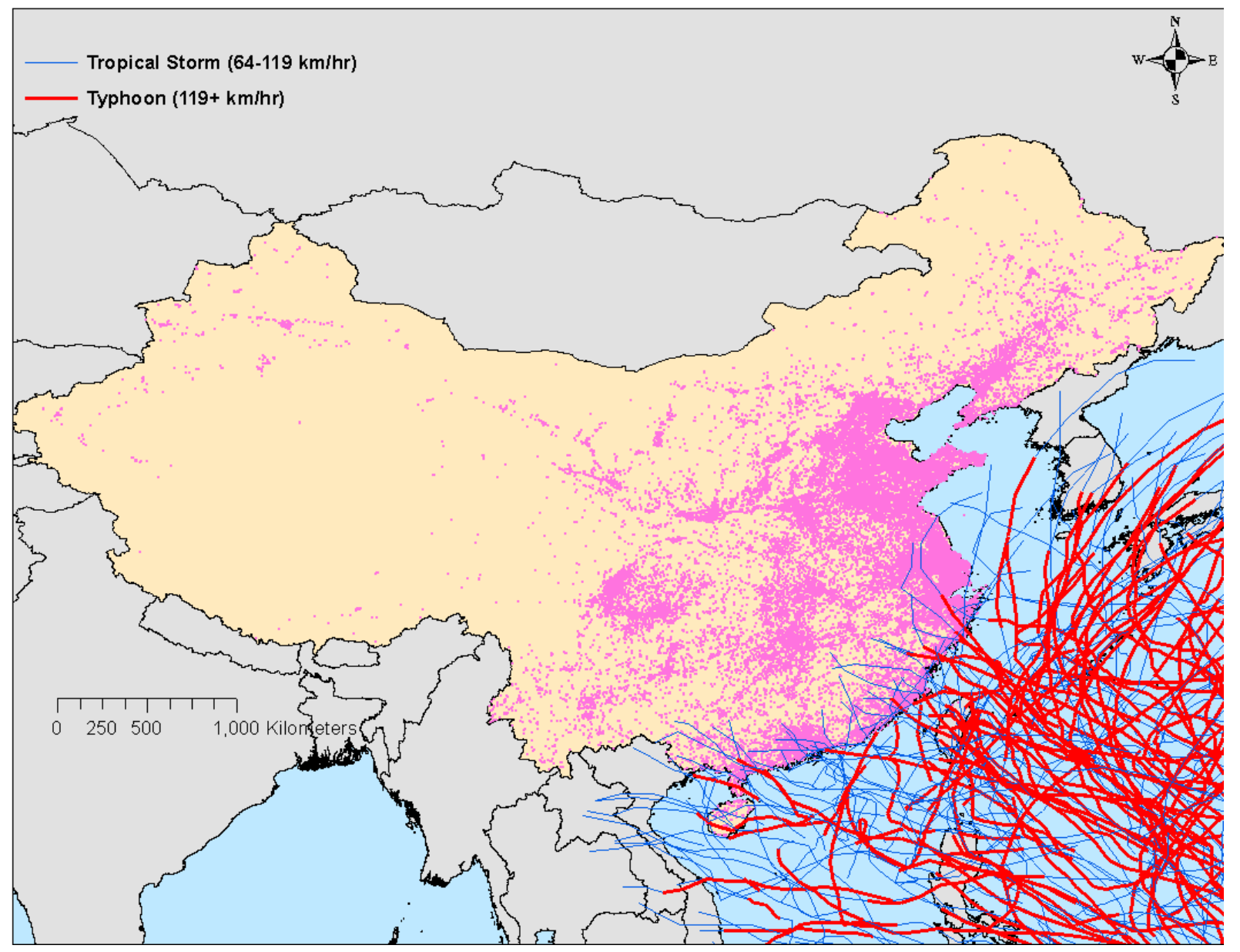


Figure 2: The Distribution of $f_{t}:$ 1998-2006

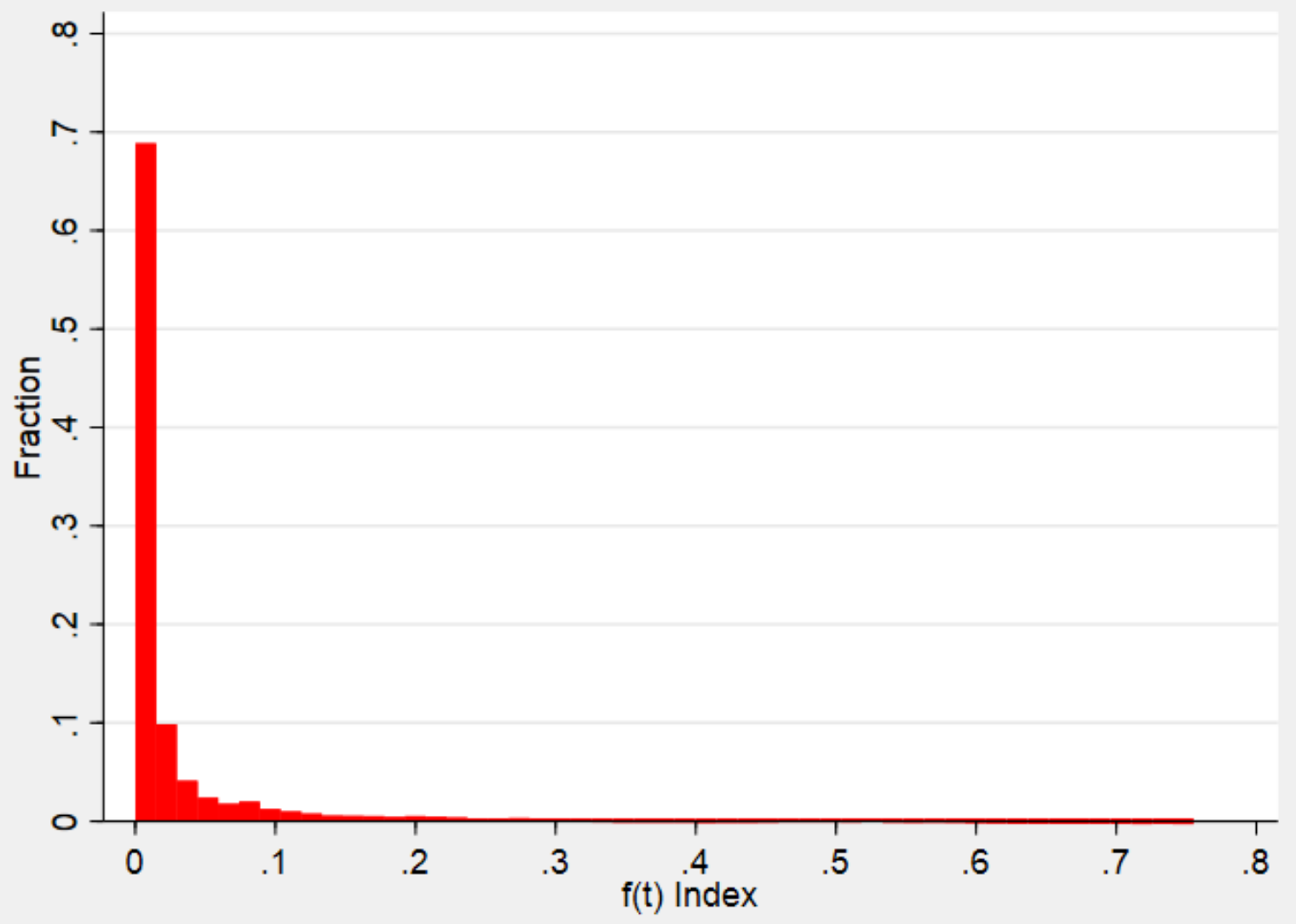


Figure 3: Fisher Type Randomization Test - Distribution of t-statistic on $f_{t}$

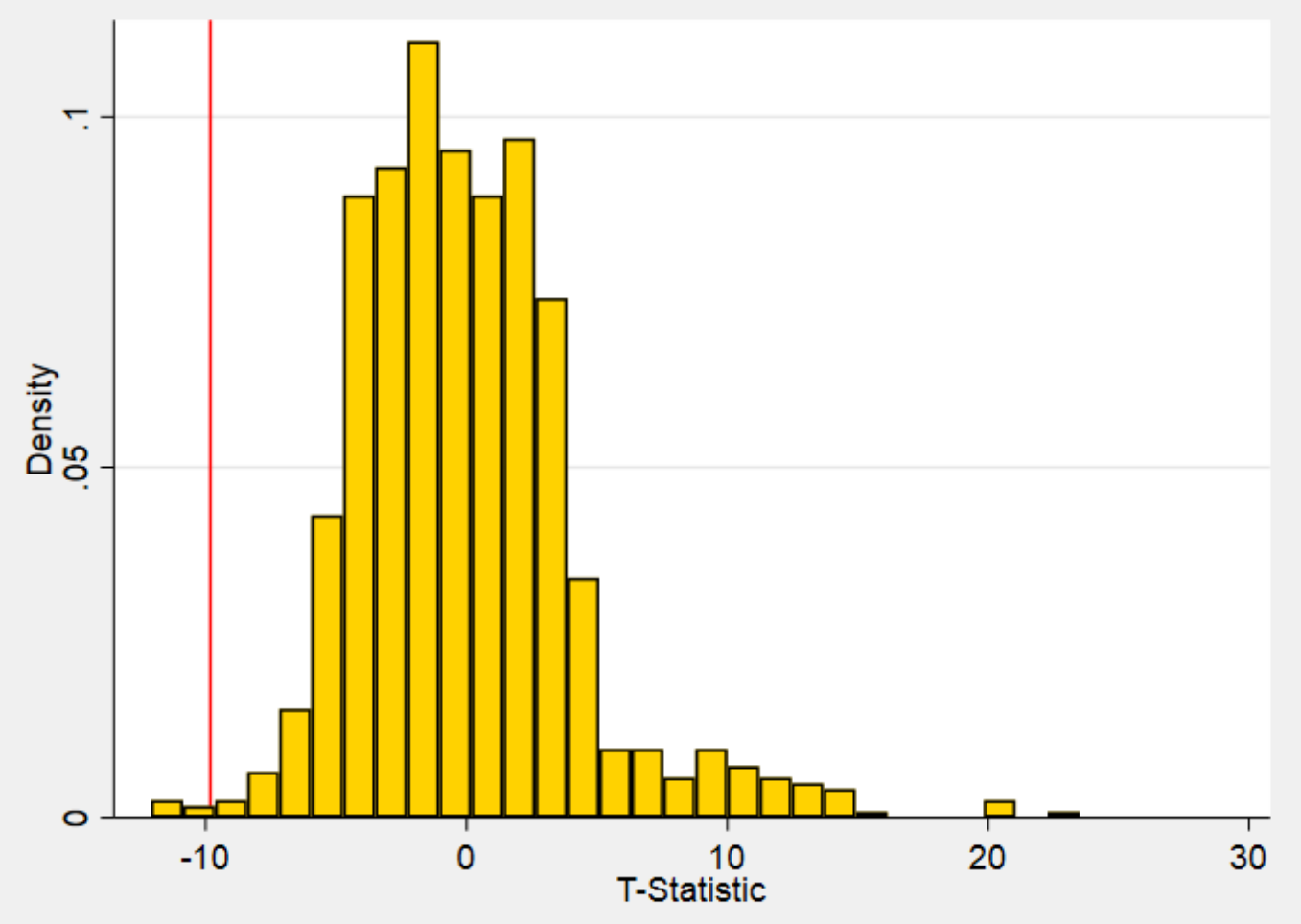


Figure 4: The Distribution of $f_{t+1}: 1998-2006$

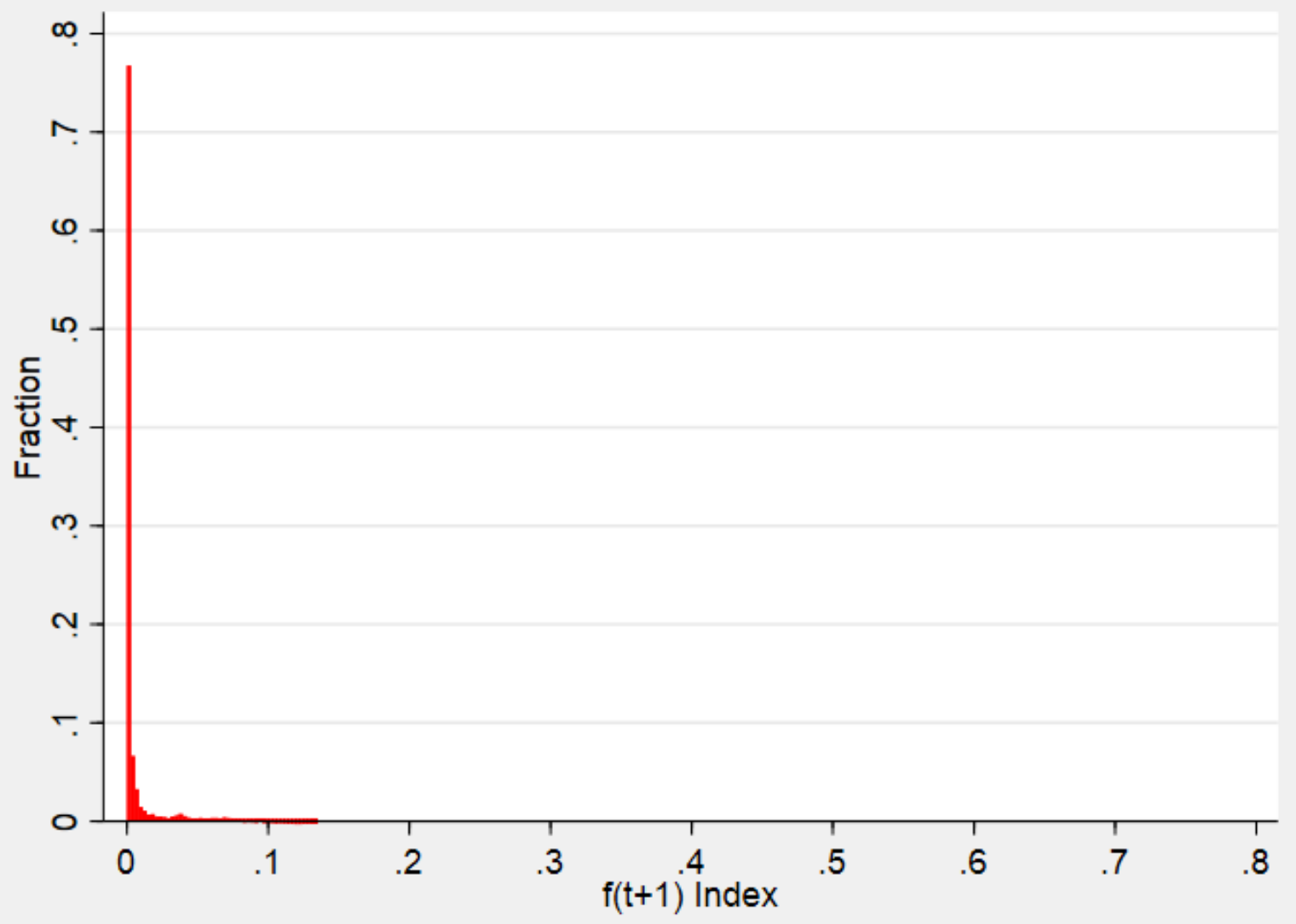


Figure 5: Fisher Type Randomization Test - Distribution of t-statistic on $f_{t+1}$

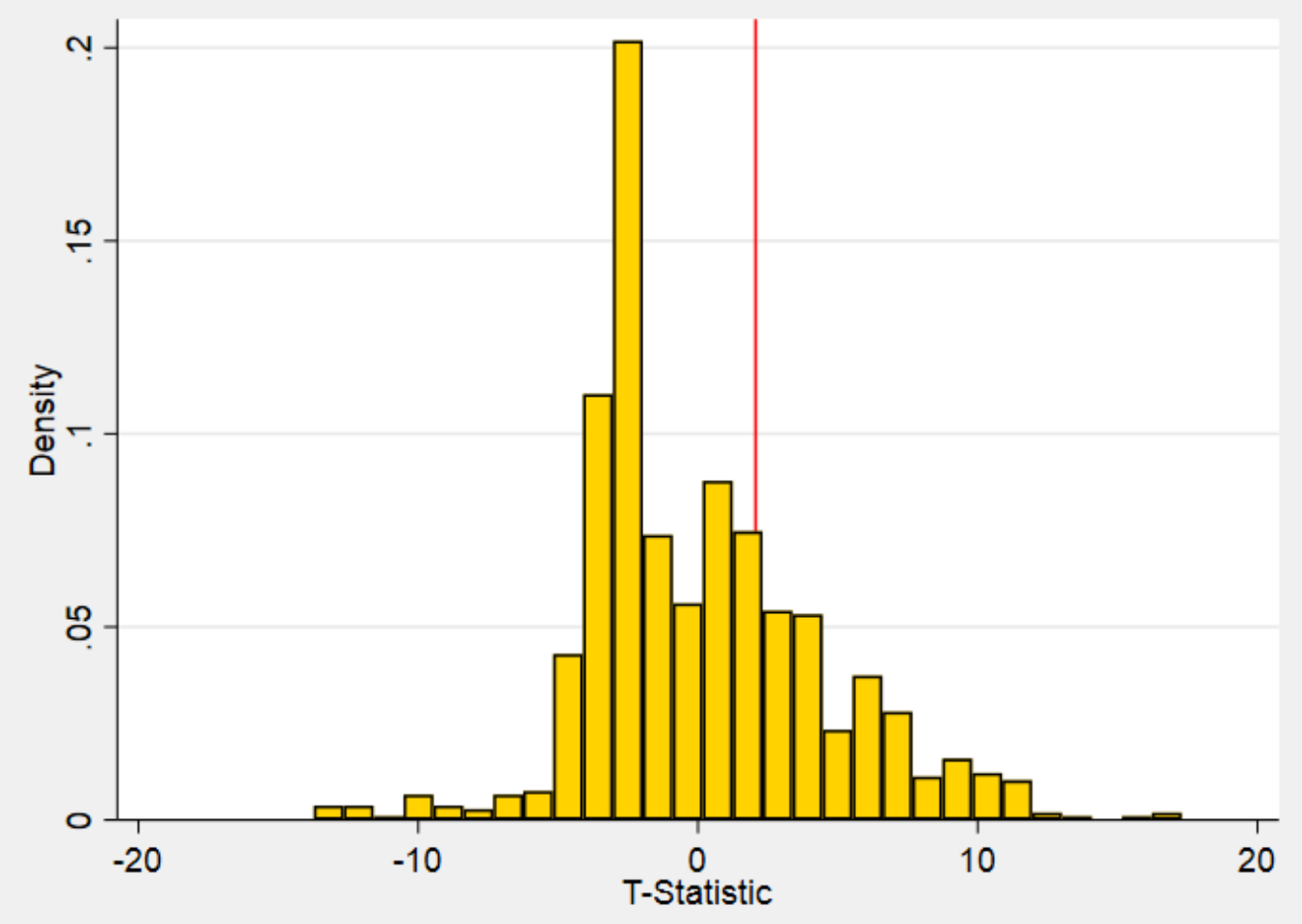


Figure 6: Spillover Regressions Results

(a) : $f$

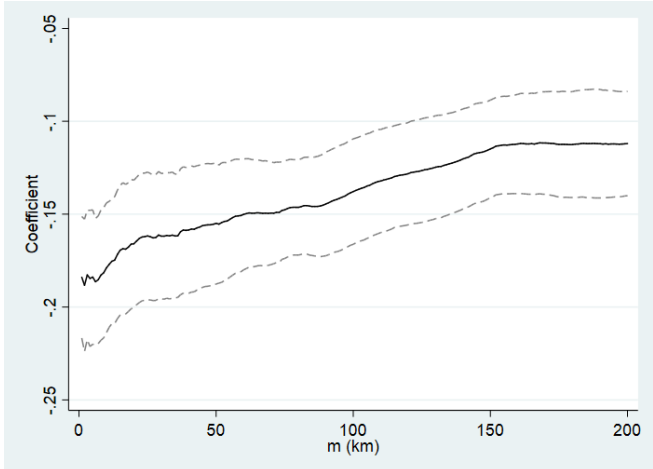

(c) : INPUTSP $(m)$

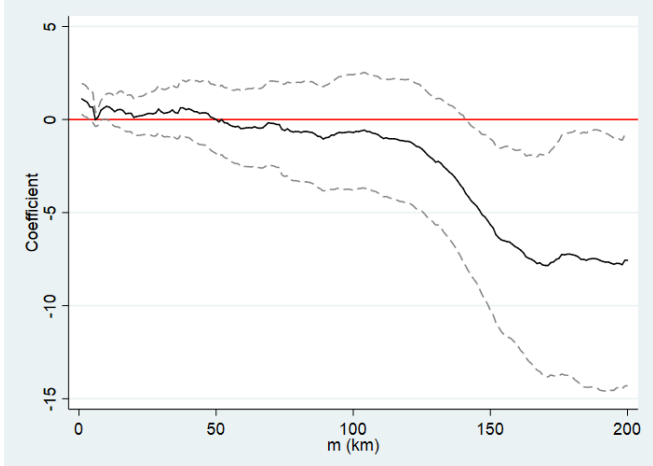

(b) : OUTPUTSP $(m)$

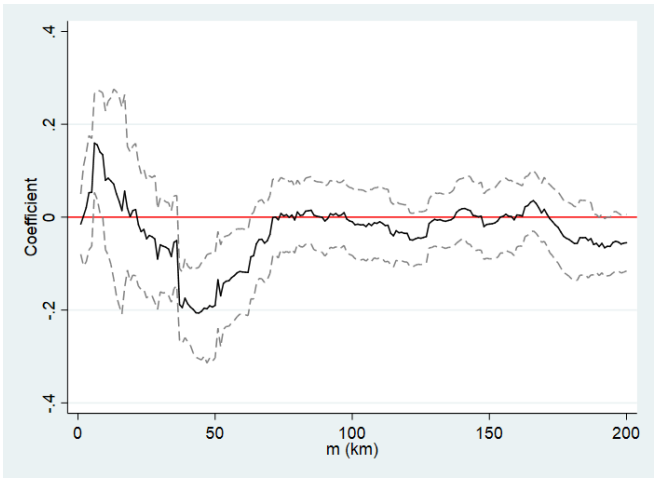

(d) : $S U P P L Y S P(m)$

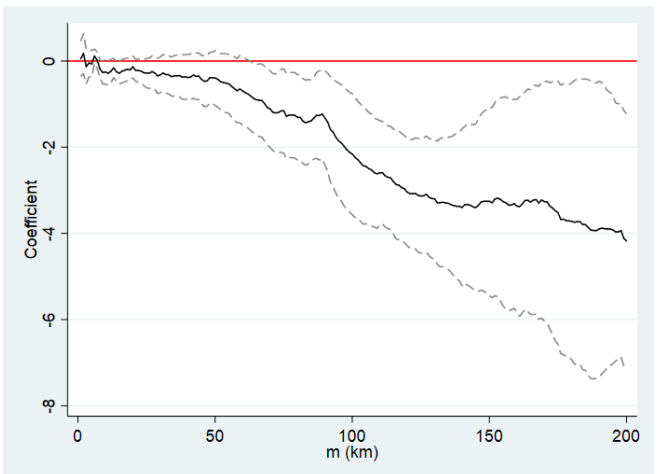




\section{Tables}

Table 1: Summary Statistics

\begin{tabular}{lll}
\hline Variable & Mean & Std.Dev. \\
\hline Turnover & 72.52 & 607.49 \\
$f$ & 0.01 & 0.04 \\
$f(f>0)$ & 0.04 & 0.09 \\
Profits & 3.59 & 54.83 \\
TFP & 6.27 & 1.13 \\
Liquidity & 0.05 & 0.35 \\
Debt & 0.59 & 0.33 \\
Wages & 12.17 & 79.60 \\
Employment & 268.03 & 979.87 \\
Inventory & 11.77 & 98.04 \\
Intermediate Inputs & 54.66 & 479.37 \\
Domestic Turnover & 64.75 & 523.57 \\
Exports & 7.77 & 240.61 \\
Imported Inputs & 5.60 & 192.84 \\
Domestic Inputs & 49.57 & 406.23 \\
\hline
\end{tabular}

Notes: (1) Turnover, Profits, Domestic Turnover, Exports, Wages, Intermediate Inputs, Inventory, and Domestic Inputs are given in 000'000s of RMB. (2) Liquidity and Debt are defined as ratio of turnover. 


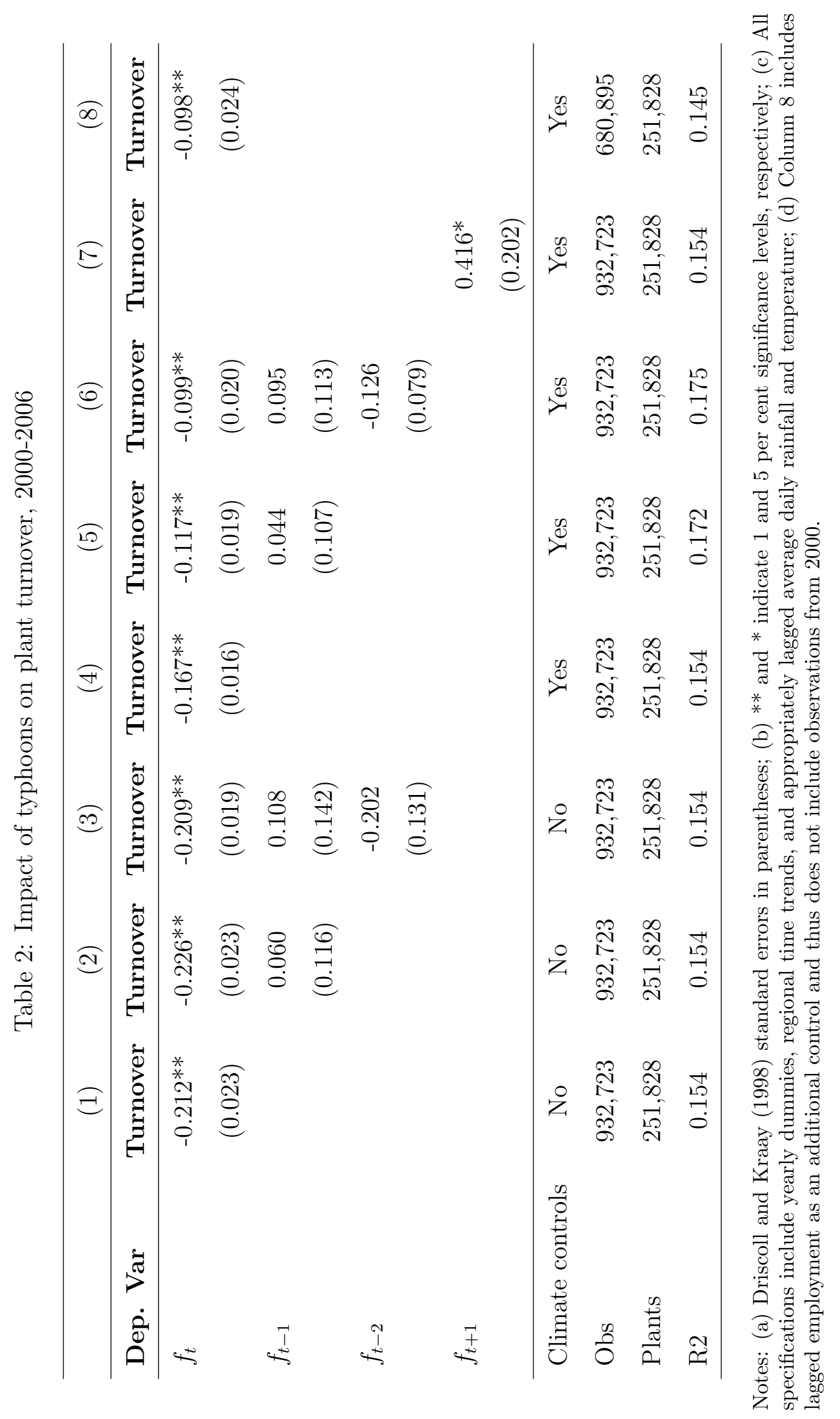




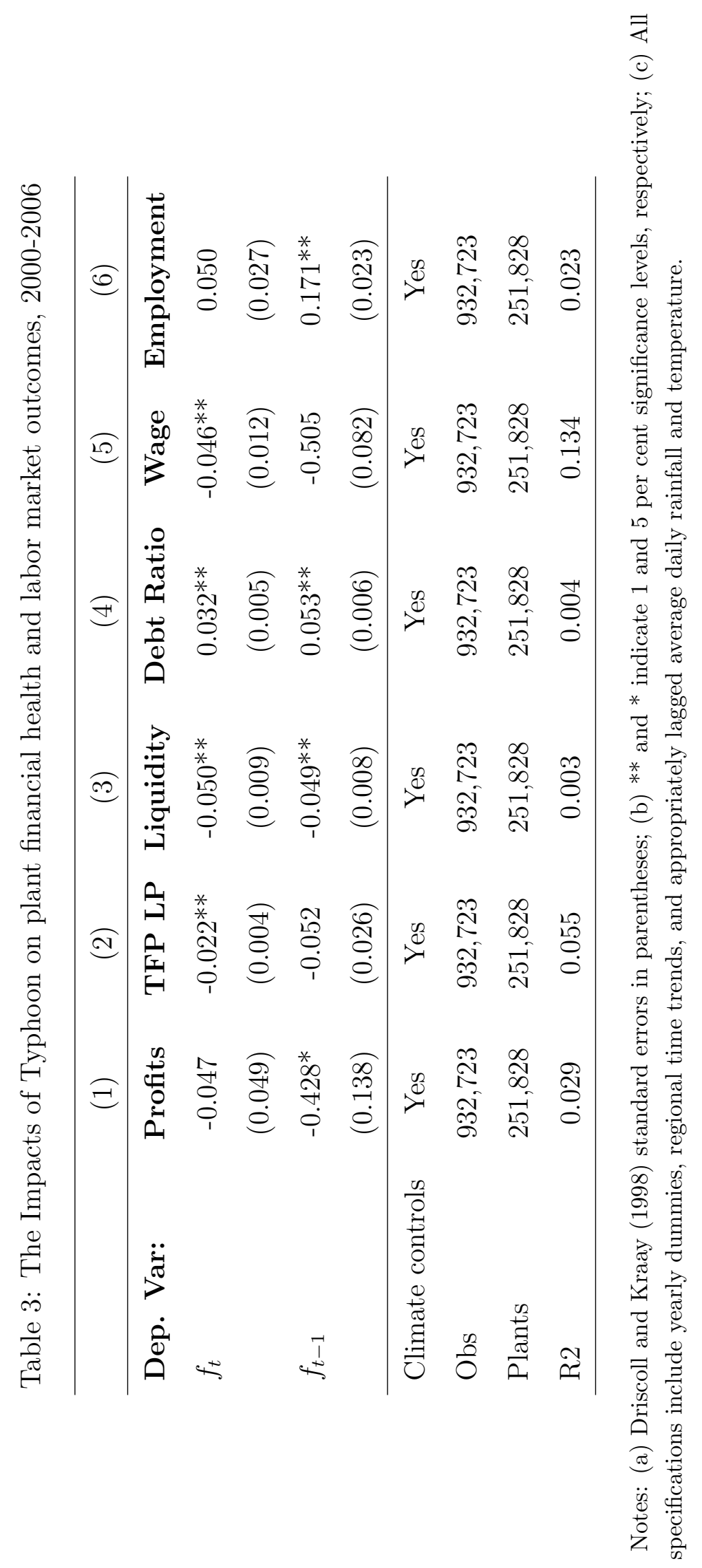




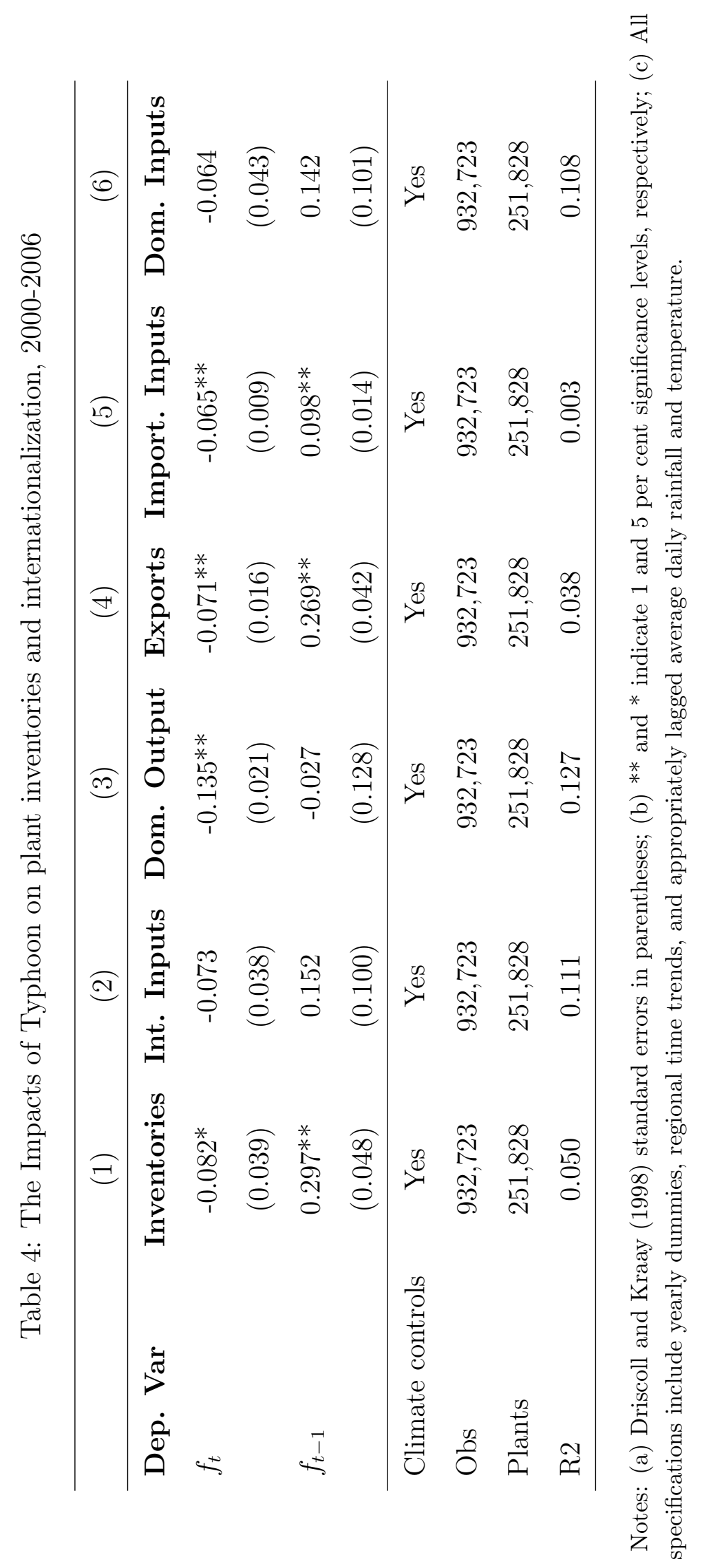




\section{References}

Ahlerup, P. (2013). Are natural disasters good for economic growth? (Tech. Rep.). University of Gothenburg, Department of Economics.

Albala-Bertrand, J.-M. (1993). Political economy of large natural disasters: With special reference to developing countries. OUP Catalogue.

Altay, N., \& Ramirez, A. (2010). Impact of disasters on firms in different sectors: Implications for supply chains. Journal of Supply Chain Management, 46(4), 59-80.

Ando, M., \& Kimura, F. (2012). How did the japanese exports respond to two crises in the international production network?: The global financial crisis and the East Japan Earthquake. ERIA Discussion Paper Series(ERIA-DP-2012-01).

Angrist, J. D., \& Pischke, J.-S. (2009). Mostly harmless econometrics: An empiricists companion. Cram101 Publishing.

Auffhammer, M., Hsiang, S. M., Schlenker, W., \& Sobel, A. (2013). Using weather data and climate model output in economic analyses of climate change. Review of Environmental Economics and Policy, 7(2), 181-198.

Bakkensen, L., \& Barrage, L. (2018). Climate shocks, cyclones, and economic growth: Bridging the micro-macro gap (Working Paper No. 24893). National Bureau of Economic Research.

Basker, E., \& Miranda, J. (2017). Taken by storm: business financing and survival in the aftermath of hurricane katrina. Journal of Economic Geography, 18(6), 1285-1313.

Bertinelli, L., \& Strobl, E. (2013). Quantifying the local economic growth impact of hurricane strikes: An analysis from outer space for the Caribbean. Journal of Applied Meteorology and Climatology, 52(8), 1688-1697.

Boose, E. R., Serrano, M. I., \& Foster, D. R. (2004). Landscape and regional impacts of hurricanes in Puerto Rico. Ecological Monographs, 74 (2), 335-352.

Brandt, L., Van Biesebroeck, J., Wang, L., \& Zhang, Y. (2017). WTO accession and performance of Chinese manufacturing firms. American Economic Review, 107(9), 2784-2820.

Brandt, L., Van Biesebroeck, J., \& Zhang, Y. (2012). Creative accounting or creative destruction? firm-level productivity growth in chinese manufacturing. Journal of Development Economics, 97, 339-351.

Brandt, L., Van Biesebroeck, J., \& Zhang, Y. (2014). Challenges of working with the Chinese NBS firm-level data. China Economic Review, 30, 339-352.

Burbidge, J. B., Magee, L., \& Robb, A. L. (1988). Alternative transformations to handle extreme values of the dependent variable. Journal of the American Statistical Association, 83(401), 123-127.

Chen, X., \& Nordhaus, W. D. (2011). Using luminosity data as a proxy for economic statistics. Proceedings of the National Academy of Sciences, 108(21), 8589-8594.

Chen, X., \& Yang, L. (2018). Temperature and industrial output: Firm-level evidence from China. Journal of Environmental Economics and Management.

Chengcheng, S., Mengya, L., Jun, W., Shiyuan, X., \& Zhenlou, C. (2014). Simulation of typhoon storm surge impacts in Shanghai based on storm surge scenarios and disaster prevention measures. Progress in Geography, 33(12), 1692-1703. 
Coelli, F., \& Manasse, P. (2014). The impact of floods on firms' performance. Working Paper DSE N 946.

Cole, M. A., Elliott, R. J. R., Okubo, T., \& Strobl, E. (2019). Natural disasters and spatial heterogeneity in damages: The birth, life and death of manufacturing plants. Journal of Economic Geography, 19(2), 373-408.

Cook, R. D. (2000). Detection of influential observation in linear regression. Technometrics, 42(1), 65-68.

Craioveanu, M., \& Terrell, D. (2016). The impact of storms on firm survival: a bayesian spatial econometric model for firm survival. In Spatial Econometrics: Qualitative and Limited Dependent Variables (pp. 81-118). Emerald Group Publishing Limited.

Crespo Cuaresma, J., Hlouskova, J., \& Obersteiner, M. (2008). Natural disasters as creative destruction? evidence from developing countries. Economic Inquiry, 46(2), 214-226.

Del Valle, A., Elliott, R. J., Strobl, E., \& Tong, M. (2018). The short-term economic impact of tropical cyclones: Satellite evidence from guangdong province. Economics of Disasters and Climate Change, 2(3), 225-235.

De Mel, S., McKenzie, D., \& Woodruff, C. (2012). Enterprise recovery following natural disasters. The Economic Journal, 122(559), 64-91.

Driscoll, J. C., \& Kraay, A. C. (1998). Consistent covariance matrix estimation with spatially dependent panel data. Review of Economics and Statistics, 80(4), 549-560.

Elliott, R. J., Strobl, E., \& Sun, P. (2015). The local impact of typhoons on economic activity in China: A view from outer space. Journal of Urban Economics, 88, 50-66.

Emanuel, K. A. (2011). Global warming effects on US hurricane damage. Weather, Climate, and Society, 3(4), 261-268.

Emanuel, K. A. (2013). Downscaling CMIP5 climate models shows increased tropical cyclone activity over the 21st century. Proceedings of the National Academy of Sciences, $110(30), 12219-12224$.

Fang, J.-Y., \& Yoda, K. (1988). Climate and vegetation in China (i). changes in the altitudinal lapse rate of temperature and distribution of sea level temperature. Ecological Research, 3(1), 37-51.

Felbermayr, G., \& Gröschl, J. (2014). Naturally negative: The growth effects of natural disasters. Journal of Development Economics, 111, 92-106.

Fischer, T., Su, B., \& Wen, S. (2015). Spatio-temporal analysis of economic losses from tropical cyclones in affected provinces of China for the last 30 years (1984-2013). Natural Hazards Review, 16(4).

Gassebner, M., Keck, A., \& Teh, R. (2010). Shaken, not stirred: the impact of disasters on international trade. Review of International Economics, 18(2), 351-368.

Groen, J., Kutzbach, M. J., \& Polivka, A. E. (2017). Storms and jobs: the effect of hurricanes on individuals' employment and earnings over the long term. BLS Working Paper, 499.

Hamaguchi, N. (2013). Market platforms, industrial clusters and small business dynamics: Specialized markets in china by ding ke, cheltenham: Edward elgar, 2012, ix + 238 pp. The Developing Economies, 51(2), 219-222.

Han, W., Liang, C., Jiang, B., Ma, W., \& Zhang, Y. (2016). Major natural disasters in China, 1985-2014: Occurrence and damages. International Journal of Environmental Research and Public Health, $13(11), 1118$. 
Hayakawa, K., Matsuura, T., \& Okubo, F. (2015). Firm-level impacts of natural disasters on production networks: Evidence from a flood in Thailand. Journal of the Japanese and International Economies, 38, 244-259.

Henderson, J. V., Storeygard, A., \& Weil, D. N. (2012). Measuring economic growth from outer space. American Economic Review, 102(2), 994-1028.

Henriet, F., Hallegatte, S., \& Tabourier, L. (2012). Firm-network characteristics and economic robustness to natural disasters. Journal of Economic Dynamics and Control, 36(1), 150-167.

Holland, G. (1980). An analytic model of the wind and pressure profiles in hurricanes. Monthly Weather Review, 108(8), 1212-1218.

Holland, G. (2008). A revised hurricane pressure--wind model. Monthly Weather Review, $136(9), 3432-3445$.

Hsiang, S. M. (2010). Temperatures and cyclones strongly associated with economic production in the Caribbean and Central America. Proceedings of the National Academy of Sciences, $107(35), 15367-15372$.

Hsiang, S. M., \& Jina, A. S. (2014). The causal effect of environmental catastrophe on long-run economic growth: Evidence from 6,700 cyclones (Working Paper No. 20352). National Bureau of Economic Research.

Inoue, H., \& Todo, Y. (2017). Propagation of negative shocks through firm networks: Evidence from simulation on comprehensive supply-chain data.

Kirchberger, M. (2017). Natural disasters and labor markets. Journal of Development Economics, 125, 40-58.

Knutson, T. R., McBride, J. L., Chan, J., Emanuel, K., Holland, G., Landsea, C., ... Sugi, M. (2010). Tropical cyclones and climate change. Nature geoscience, 3(3), 157.

Leiter, A. M., Oberhofer, H., \& Raschky, P. A. (2009). Creative disasters? flooding effects on capital, labour and productivity within European firms. Environmental and Resource Economics, 43(3), 333-350.

LeSage, J. P., Kelley Pace, R., Lam, N., Campanella, R., \& Liu, X. (2011). New Orleans business recovery in the aftermath of Hurricane Katrina. Journal of the Royal Statistical Society: Series A (Statistics in Society), 174(4), 1007-1027.

Levinsohn, J., \& Petrin, A. (2003). Estimating production functions using inputs to control for unobservables. The Review of Economic Studies, 70(2), 317-341.

Li, X., Wang, L., Chen, D., Yang, K., Xue, B., \& Sun, L. (2013). Near-surface air temperature lapse rates in the mainland China during 1962-2011. Journal of Geophysical Research: Atmospheres, 118(14), 7505-7515.

Liu, Y. (2016). Trade liberalization and wage differentials of heterogeneous firms: Three empirical studies of Chinese firms (Unpublished doctoral dissertation). University of Birmingham.

Lixin, Y., Lingling, G., Dong, Z., Junxue, Z., \& Zhanwu, G. (2012). An analysis on disasters management system in China. Natural hazards, 60(2), 295-309.

Loayza, N. V., Olaberria, E., Rigolini, J., \& Christiaensen, L. (2012). Natural disasters and growth: Going beyond the averages. World Development, 40(7), 1317-1336.

Manova, K., \& Zhang, Z. (2012). Export prices across firms and destinations. The Quarterly Journal of Economics, 127(1), 379-436. 
Nicolls, M., Kelley, M., Vlasov, M., Sahai, Y., Chau, J., Hysell, D., ... Lima, W. (2006). Observations and modeling of post-midnight uplifts near the magnetic equator. In Annales geophysicae (Vol. 24, pp. 1317-1331).

Noy, I., \& duPont IV, W. (n.d.). The long-term consequences of natural disasters - a summary of the literature. SEF Working paper 02/2016.

Parsons, C. R. (2016). Disasters and trade: Did Hurricane Katrina affect US imports? International Economics and Economic Policy, 13(2), 177-194.

Paulsen, B. M., \& Schroeder, J. L. (2005). An examination of tropical and extratropical gust factors and the associated wind speed histograms. Journal of Applied Meteorology, $44(2), 270-280$.

Paxson, C., \& Rouse, C. E. (2008). Returning to New Orleans after Hurricane Katrina. American Economic Review, 98(2), 38-42.

Shi, P., Liu, J., Yao, Q., Tang, D., \& Yang, X. (2007). Integrated disaster risk management of China.. (Korean Society of Environmental Toxicology. Paper presented at the Autumn Conference)

Strobl, E. (2011). The economic growth impact of hurricanes: evidence from US coastal counties. Review of Economics and Statistics, 93(2), 575-589.

Strobl, E. (2012). The economic growth impact of natural disasters in developing countries: Evidence from hurricane strikes in the Central American and Caribbean regions. Journal of Development Economics, 97(1), 130-141.

Tanaka, A. (2015). The impacts of natural disasters on plants' growth: Evidence from the Great Hanshin-Awaji (Kobe) earthquake. Regional Science and Urban Economics, 50, $31-41$.

Tang, Z., \& Fang, J. (2006). Temperature variation along the northern and southern slopes of Mt. Taibai, China. Agricultural and Forest Meteorology, 139(3-4), 200-207.

Tol, R. S. (1999). Economic analysis of natural disasters. Climate, Change and Risk, 308-327.

Upward, R., Wang, Z., \& Zheng, J. (2013). Weighing China's export basket: The domestic content and technology intensity of Chinese exports. Journal of Comparative Economics, 41(2), 527-543.

Vickery, P. J., Masters, F. J., Powell, M. D., \& Wadhera, D. (2009). Hurricane hazard modeling: The past, present, and future. Journal of Wind Engineering and Industrial Aerodynamics, 97(7-8), 392-405.

Vu, T. B., \& Noy, I. (2018). Natural disasters and firms in Vietnam. Pacific Economic Review, 23(3), 426-452.

Wang, J. (2010). Catastrophe insurance policy for China (Tech. Rep. No. 17). The World Bank.

Wang, Z., Chan, E. Y., Liu, K., Sida, Y., \& May, P. (2016). Policy brief: The disaster and emergency management system in China (Tech. Rep.). Collaborating Centre for Oxford University and CUHK for Disaster and Medical Humanitarian Response (CCOUC). The Chinese University of Hong Kong.

Xiao, Y., Xiao, Y., \& Duan, Z. (2009). The typhoon wind hazard analysis in Hong Kong of China with the new formula for Holland B parameter and the CE wind field model. In Proc. seventh asia-pacific conf. on wind engineering. 
Yang, W., Chen, B., \& Cui, X. (2014). High-resolution mapping of anthropogenic heat in China from 1992 to 2010. International Journal of Environmental Research and Public Health, 11(4), 4066-4077.

Zhang, P., Deschenes, O., Meng, K., \& Zhang, J. (2018). Temperature effects on productivity and factor reallocation: Evidence from a half million Chinese manufacturing plants. Journal of Environmental Economics and Management, 88, 1-17.

Zhang, Q., Wu, L., \& Liu, Q. (2009). Tropical cyclone damage in China: 1983-2006. Bulletin of the American Meteorological Society, 90(4), 489-495. 


\section{Appendices}

\section{A Detailed Data Description}

\section{A.1 Firm Level Data}

CASIF data includes all firms with over 5 million RMB in annual turnover and all state owned enterprises. In this paper we focus only on manufacturing firms and hence exclude firms from the mining sector and electric power, gas and water production and supply, and the firms from the tobacco, handicrafts and recycling industries. We then match the manufacturing firms' data with the Chinese Customs data, which provides comprehensive trade transaction records. Following Manova and Zhang (2012), we also exclude firms that act as trading agents, who those are not engaged in the production of good and hence only provide various kinds of trading services, such as exporting or importing products for other firms, or temporarily storing or shipping products for other firms. The data cleaning rules for users of the CSIF data are now fairly well established, see ? (?), and we follow these closely in that we exclude firms with less than 8 employees. Additionally we do the following:

For completeness we outline our cleaning rules below. Firms with variables exhibiting the characteristics listed as below are also excluded from our sample:

1. Firms with missing location information, specifically without a region code.

2. Firms that report missing, zero or negative values for any of the financial variables related to final outputs, intermediate inputs, sales, revenue, profits, total capital and wages.

3 . Firms that report missing or negative values for any of the financial variables related to a firm's ownership structure, e.g. a firm with a negative value for its foreign capital is invalid, but a firm with zero foreign capital is valid, which may be a result of no foreign investment. 4. Firms with missing or negative values of exporting final outputs and importing intermediate inputs.

5. Firms where the value of production is less than the export value.

6 . Firms where the total value of inputs used in production is less than the import value of intermediate inputs.

7. Firms with missing values for employment or have less than eight employees.

8. Firms who report missing values for any of the financial variables related to assets.

9. Firms whose liquid assets are higher than total assets; or firms whose total fixed assets are higher than total assets; or firms whose net fixed assets are higher than total assets. 10. Firms whose birth year or established year is missing and invalid.

11. Firms ID based on the industrial data set system is missing.

12. Processing firms with non-zero values of processing exports or processing imports.

In terms of linking plants via their unique ID over time, there were 109,530 plants that appear only once in our sample period, constituting approximately $29.8 \%$ of all plants, and we necessarily dropped these. As a result of the cleaning process just described we have an unbalanced panel with 932,723 observations for 251,828 unique firms for 2000-2006. Finally, one should not that we use 4-digit output and input deflators from Brandt et al. (2012) to deflate all monetary variables and then convert those deflated values into millions RMB in 
1998 prices. The average exchange rate between the RMB and the USD during our sample period (2000-2006) is around 8.22 RMB to 1 USD.

\section{A.2 Input-Output Table}

The 2002 Input-Output Table includes 122 sectors and there are 6 sectors for agriculture, 6 sectors for mining, 71 sectors for manufacturing, 1 sector for scrap and waste, 3 sectors for electricity, gas and water production and supply, 1 sector for construction, 9 sectors for transport and warehouse, 1 sector for post, 1 sector for wholesale and retail trade services, 1 sector for food serving services, and 22 sectors for other services. The manufacturing sectors are:

13 Manuf. agricultural products

14 Manuf. food products

15 Manuf. drink products

17 Manuf. textile products

18 Manuf. apparel, footwear etc.

19 Manuf. leather products, fur etc.

20 Manuf. wood and wood products

21 Furniture manufacturing

22 Manuf. paper, paper products

23 Printing and reproduction media

24 Manuf. cultural and entertainment products

25 Processing crude oil, nuclear fuel

26 Manuf. chemical raw materials

27 Manuf. pharmaceuticals

28 Manuf. chemical fibres

29 Manuf. rubber products

30 Manuf. plastic products

31 Manuf. non-metal products

32 Manuf. ferrous metal casting

33 Manuf. non-ferrous metal casting

34 Manuf. metal products

35 Manuf. universal equipment

36 Manuf. special equipment

37 Manuf. transportation equipment

39 Manuf. electric machines, appliances

40 Manuf. electronic equipment

41 Manuf. instruments, appliances

\section{B Additional Tables}


Table A1: Definitions of our economic indicators

\begin{tabular}{l|l}
\hline Economic Indicator & Definition \\
\hline TFP_LP & Total Factor Productivity calculated following Levinsohn-Petrin (2003). \\
Exports & Value of exports (million RMB). \\
Imports & Value of imports (million RMB). \\
Turnover & Value of sales (million RMB). \\
Inventories & Value of intermediate inputs (million RMB). \\
Intermediate Inputs & Value of domestic outputs (million RMB). \\
Domestic Output & Value of domestic inputs (million RMB). \\
Domestic Inputs & Average wage per employee (thousand RMB). \\
Mean Wage & Total liabilities over total assets. \\
Debt_ratio & (Liquid assets - Current liabilities) over total assets. \\
Liquidity_ratio & Total profits (million RMB). \\
Profits & Number of employees (all employees). \\
Employment & arion RMB).
\end{tabular}

Note: All monetary values are deflated to 1998 prices using 4-digit sector deflators (see Brandt et al. 2014 and Brandt et al. 2017 for details). 
Table A2: Damaging Typhoons in China 2000-2006

\begin{tabular}{|c|c|c|c|c|}
\hline Name & Year & Max. Wind Speed $(\mathrm{km} / \mathrm{hr})$ & Damage (bln. RMB) & Damage (\$US bln.) \\
\hline Bilis & 2000 & 203 & 8.40 & 1.243 \\
\hline Jelawat & 2000 & 157 & 0.481 & 0.071 \\
\hline Prapiroon & 2000 & 130 & 4.74 & 1.273 \\
\hline Saomai & 2000 & 176 & 3.316 & 0.891 \\
\hline Wukong & 2000 & 139 & 1.398 & 0.376 \\
\hline Maria & 2000 & 130 & 2.628 & 0.706 \\
\hline Kai-tak & 2000 & 139 & 0.675 & 0.181 \\
\hline Chebi & 2001 & 120 & 4.61 & 1.214 \\
\hline Durian & 2001 & 111 & 6.572 & 1.730 \\
\hline Nari & 2001 & 139 & 0.06 & 0.016 \\
\hline Toraji & 2001 & 139 & 3.463 & 0.912 \\
\hline Utor & 2001 & 111 & 16.965 & 4.467 \\
\hline Yutu & 2001 & 102 & 0.882 & 0.232 \\
\hline Fitow & 2001 & 74 & 1.972 & 0.519 \\
\hline Trami & 2001 & 65 & 0.041 & 0.011 \\
\hline Hagupit & 2002 & 84 & 0.35 & 0.092 \\
\hline Kammuri & 2002 & 102 & 5.7 & 1.492 \\
\hline Mekkhala & 2002 & 102 & 1.1 & 0.288 \\
\hline Sinlaku & 2002 & 148 & 8.1 & 2.120 \\
\hline Vongfong & 2002 & 102 & 2.9 & 0.759 \\
\hline Dujuan & 2003 & 148 & 2.49 & 0.635 \\
\hline Krovanh & 2003 & 120 & 3.18 & 0.811 \\
\hline Imbudo & 2003 & 167 & 3.3 & 0.842 \\
\hline Nepartak & 2003 & 111 & 1.63 & 0.416 \\
\hline Koni & 2003 & 111 & 0.19 & 0.048 \\
\hline Vamco & 2003 & 65 & 0.07 & 0.018 \\
\hline Malou & 2004 & 55 & 0.031 & 0.007 \\
\hline Aere & 2004 & 148 & 3.231 & 0.771 \\
\hline Rananim & 2004 & 148 & 20.295 & 4.840 \\
\hline Haima & 2004 & 75 & 0.053 & 0.013 \\
\hline Mindulle & 2004 & 167 & 0.408 & 0.097 \\
\hline Damrey & 2005 & 148 & 12.21 & 2.802 \\
\hline Haitang & 2005 & 194 & 10.78 & 2.474 \\
\hline Khanun & 2005 & 157 & 14.11 & 3.239 \\
\hline Longwang & 2005 & 176 & 7.81 & 1.793 \\
\hline Matsa & 2005 & 148 & 18.04 & 4.141 \\
\hline Talim & 2005 & 176 & 15.35 & 3.523 \\
\hline Sanvu & 2005 & 93 & 3.01 & 0.691 \\
\hline Washi & 2005 & 83 & 0.04 & 0.009 \\
\hline Chanchu & 2006 & 176 & 8.386 & 1.852 \\
\hline Jelawat & 2006 & 83 & 0.03 & 0.007 \\
\hline Kaemi & 2006 & 148 & 5.752 & 1.270 \\
\hline Prapiroon & 2006 & 120 & 7.865 & 1.737 \\
\hline Saomai & 2006 & 194 & 19.658 & 4.341 \\
\hline Bilis & 2006 & 204 & 34.829 & 7.692 \\
\hline
\end{tabular}

Data source: List of damaging tropical storm to China and direct Economic Loss is collected from China Yearbooks of Meteorological Disaster; Maximum wind speed is collected from Regional Specialized Meteorological Centre (RSMC); Annual China GDP deflators and exchange rate between RMB and US dollars are from Federal Reserve Bank of St Louis. Damage estimates are in 2017 prices. 